\title{
European guidance for the diagnosis and management of osteoporosis in postmenopausal women
}

\author{
J. A. Kanis $\cdot$ N. Burlet $\cdot$ C. Cooper $\cdot$ P. D. Delmas • \\ J.-Y. Reginster $\cdot$ F. Borgstrom $\cdot$ R. Rizzoli • \\ on behalf of the European Society for Clinical \\ and Economic Aspects of Osteoporosis \\ and Osteoarthritis (ESCEO)
}

Received: 31 October 2007 / Accepted: 20 November 2007 / Published online: 12 February 2008

(C) International Osteoporosis Foundation and National Osteoporosis Foundation 2008

\begin{abstract}
Summary Guidance is provided in a European setting on the assessment and treatment of postmenopausal women with or at risk from osteoporosis.

Introduction The European Foundation for Osteoporosis and Bone disease (subsequently the International Osteopo-
\end{abstract}

\section{J. A. Kanis $(\bowtie)$}

WHO Collaborating Centre for Metabolic Bone Diseases,

University of Sheffield Medical School,

Beech Hill Road,

Sheffield S10 2RX, UK

e-mail: w.j.Pontefract@shef.ac.uk

N. Burlet

IOF (International Osteoporosis Foundation),

Nyon, Switzerland

C. Cooper

MRC Epidemiology Resource Centre,

University of Southampton,

Southampton, UK

P. D. Delmas

University of Lyon and INSERM Research Unit 831,

Lyon, France

\section{J.-Y. Reginster}

WHO Collaborating Center for Public Health Aspect

of Rheumatic Diseases, University of Liège,

CHU Centre Ville,

Liège, Belgium

F. Borgstrom

i3 innovus,

Stockholm, Sweden

R. Rizzoli

Service of Bone Diseases (WHO Collaborating Center for Osteoporosis Prevention) Geneva University Hospitals, Geneva, Switzerland rosis Foundation) published guidelines for the diagnosis and management of osteoporosis in 1997. This manuscript updates these in a European setting.

Methods The following areas are reviewed: the role of bone mineral density measurement for the diagnosis of osteoporosis and assessment of fracture risk; general and pharmacological management of osteoporosis; monitoring of treatment; assessment of fracture risk; case finding strategies; investigation of patients; health economics of treatment.

Results and conclusions A platform is provided on which specific guidelines can be developed for national use.

Keywords Bone mineral density .

Diagnosis of osteoporosis · Fracture risk assessment .

Health economics $\cdot$ Treatment of osteoporosis

Preamble 1997 The European Foundation for Osteoporosis and Bone Disease (subsequently the International Osteoporosis Foundation) published guidelines for the diagnosis and management of osteoporosis [1]. Since then, there have been significant advances in the field of osteoporosis. These include the development of many new techniques for measuring bone mineral, improved methods of assessing fracture risk and new treatments that have been shown to significantly reduce the risk of fractures at vulnerable sites. Against this background, the Scientific Advisory Board of the European Society for Clinical and Economic Evaluation of Osteoporosis and Osteoarthritis (ESCEO), in collaboration with the International Osteoporosis Foundation, has recognised a need to revise the original guidelines which are detailed below. The term guideline is supplanted by the term guidance, to avoid any prescriptive connotations since country or region specific guidelines are now widely available. Rather, the guidance can inform the development of new guidelines or the 
revision of existing guidelines. They are focussed on a European perspective, since there are some differences of approach in other regions of the world.

\section{Introduction}

Osteoporosis is defined as a systemic skeletal disease characterised by low bone mass and microarchitectural deterioration of bone tissue, with a consequent increase in bone fragility and susceptibility to fracture [1]. Although the diagnosis of the disease relies on the quantitative assessment of bone mineral density (BMD), which is a major determinant of bone strength, the clinical significance of osteoporosis lies in the fractures that arise. In this respect, there are some analogies with other multifactorial chronic diseases. For example, hypertension is diagnosed on the basis of blood pressure, whereas an important clinical consequence of hypertension is stroke.

Common sites for osteoporotic fracture are the spine, hip, distal forearm and proximal humerus. The remaining lifetime probability in women at the menopause of a fracture at any one of these sites exceeds that of breast cancer (approximately 12\%), and the likelihood of a fracture at any of these sites is $40 \%$ or more in developed countries (Table 1) [2], a figure close to the probability of coronary heart disease. In the year 2000 , there were estimated to be 620,000 new fractures at the hip, 574,000 at the forearm, 250,000 at the proximal humerus and 620,000 clinical spine fractures in men and women aged 50 years or over in Europe. These fractures accounted for $34.8 \%$ of such fractures worldwide [3]. Osteoporotic fractures also occur at many other sites including the pelvis, ribs, and distal femur and tibia. Collectively, all osteoporotic fractures account for 2.7 million fractures in men and women in Europe at a direct cost of 36 billion Euros [4].

Osteoporotic fractures are a major cause of morbidity in the population. Hip fractures cause acute pain and loss of function, and nearly always lead to hospitalisation. Recovery is slow and rehabilitation is often incomplete, with many

Table 1 Remaining lifetime probability (\%) of common osteoporotic fractures in Swedish men and women aged 50 years. (Reprinted from [2], with kind permission from Springer Science + Business Media)

\begin{tabular}{lll}
\hline Site of fracture & $\begin{array}{l}\text { Women aged } \\
50 \text { years }\end{array}$ & $\begin{array}{l}\text { Men aged } \\
50 \text { years }\end{array}$ \\
\hline Hip & 22.9 & 10.7 \\
Distal forearm & 20.8 & 4.6 \\
Spine (clinical) & 15.1 & 8.3 \\
Proximal humerus & 12.9 & 4.9 \\
Any of the above & 46.4 & 22.4 \\
\hline
\end{tabular}

patients permanently institutionalised in nursing homes. Vertebral fractures may cause acute pain and loss of function, but may also occur without serious symptoms. Vertebral fractures often recur, however, and the consequent disability increases with the number of fractures. Distal radial fractures also lead to acute pain and loss of function, but functional recovery is usually good or excellent.

It is widely recognised that osteoporosis and the consequent fractures are associated with increased mortality, with the exception of forearm fractures [5]. In the case of hip fracture, most deaths occur in the first 3-6 months following the event, of which $20-30 \%$ is causally related to the fracture event itself. The estimates of deaths from Sweden that are causally related to hip fracture are appreciable and suggest that more than $1 \%$ of all deaths are due to hip fracture [6], somewhat higher than the percentage of deaths attributed to pancreatic cancer and somewhat lower than the percentage of deaths attributed to breast cancer (Table 2).

A general approach to quantifying the burden of disease, favoured by the WHO and World Bank, is to assess the disability incurred by disease, including deaths due to the disorder as well as the disability that arises in survivors [7]. The approach, based on disability and life-years lost (DALYs), permits a comparison with other disease states. Figures 1 and 2 show the burden in Europe compared with that for other chronic diseases. Osteoporosis accounted for more DALYs than rheumatoid arthritis, but fewer than osteoarthritis. With regard to neoplastic diseases, the burden of osteoporosis was greater than for all sites of cancer, with the exception of lung cancers [3].

Table 2 Principal causes of death from selected diseases in Swedish men and women in 1998. (Reprinted from [6], with permission from Elsevier)

\begin{tabular}{lllll}
\hline & Men & Women & Total & $\%$ \\
\hline Acute myocardial infarction & 7,113 & 5,335 & 12,448 & 13.3 \\
Cardiovascular accident & 4,411 & 6,069 & 10,480 & 11.2 \\
Lung cancer & 1,761 & 1,112 & 2,873 & 3.1 \\
Prostate cancer & 2,480 & 0 & 2,480 & 2.6 \\
Chronic obstructive airways & 944 & 723 & 1,667 & 1.8 \\
$\quad$ disease & & & & \\
Diabetes & 744 & 819 & 1,563 & 1.7 \\
Breast cancer & 11 & 1,549 & 1,560 & 1.7 \\
Hip fracture & 566 & 854 & 1,420 & 1.5 \\
Pancreatic cancer & 603 & 736 & 1,339 & 1.4 \\
Suicide & 880 & 349 & 1,229 & 1.3 \\
Atrial fibrillation & 413 & 687 & 1,091 & 1.2 \\
Stomach cancer & 489 & 334 & 823 & 0.9 \\
Transport accidents & 422 & 142 & 564 & 0.6 \\
Smoke inhalation and fire & 85 & 53 & 138 & 0.2 \\
All deaths & 46,840 & 46,788 & 93,628 & 100 \\
\hline
\end{tabular}




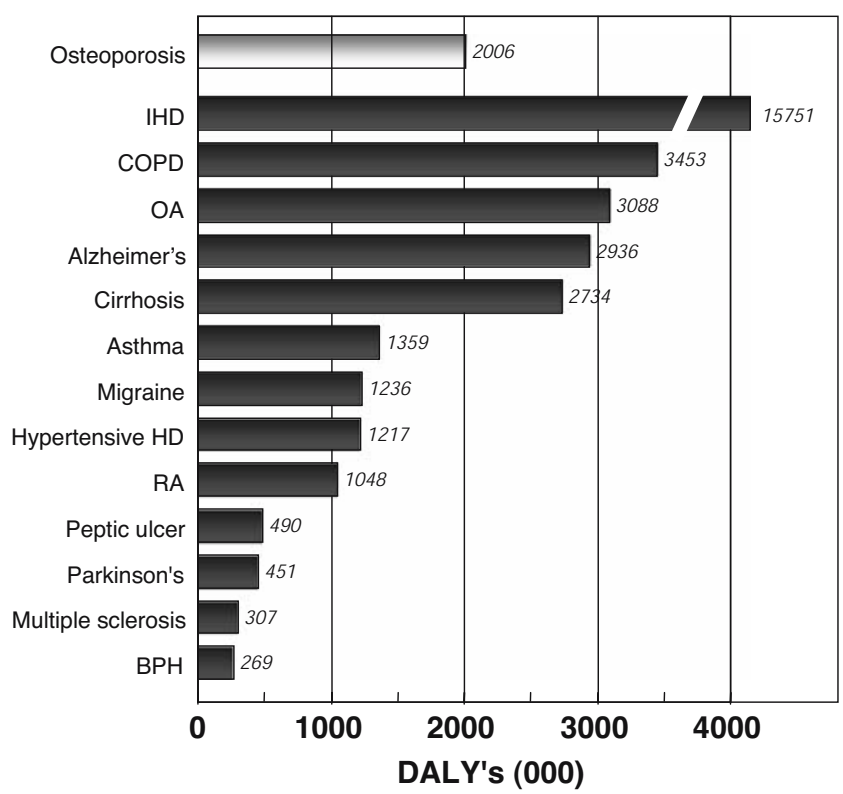

Fig. 1 Burden of diseases estimated as disability-adjusted life-years (DALYs) lost due to a selection of non-communicable diseases in Europe. (Reprinted from [3], with kind permission from Springer Science + Business Media). IHD ischaemic heart disease, COPD chronic obstructive pulmonary disease, $O A$ osteoarthritis, $R A$ rheumatoid arthritis, $B P H$ benign prostatic hyperplasia

The high societal and personal costs of osteoporosis pose challenges to public health and physicians, particularly since most patients with osteoporosis remain untreated. The aims of this guidance are to stimulate a cohesive approach to the management of osteoporosis in Europe. Although the guidance is focussed on postmenopausal women, the same general principles apply to men as well as women.

\section{Bone mineral measurements and diagnosis of osteoporosis}

The objectives of bone mineral measurements are to provide diagnostic criteria, prognostic information on the probability of future fractures, and a baseline on which to monitor the natural history of the treated or untreated patient. BMD is the amount of bone mass per unit volume (volumetric density), or per unit area (areal density), and both can be measured in vivo by densitometric techniques.

Techniques to measure bone mineral

A wide variety of techniques is available to assess bone mineral that are reviewed elsewhere [8-10]. The most widely used are based on X-ray absorptiometry in bone, particularly dual-energy X-ray absorptiometry (DXA) since the absorption of X-rays is very sensitive to the calcium content of the tissue of which bone is the most important source. Other techniques include quantitative ultrasound (QUS), quantitative computed tomography (QCT), both applied to the appendicular skeleton and to the spine, peripheral DXA, digital X-ray radiogrammetry, radiographic absorptiometry, and other radiographic techniques. Other important determinants of bone strength for both cortical and trabecular bone include macro- and microarchitecture. $\mathrm{X}$-ray-based technology is becoming available to estimate these components of bone strength.

Dual-energy X-ray absorptiometry (DXA) is the most widely used bone densitometric technique. It is versatile in the sense that it can be used to assess bone mineral content of the
Fig. 2 Burden of diseases estimated as disability-adjusted life-years (DALYs) lost due to a selection of neoplastic diseases in Europe. (Reprinted from [3], with kind permission from Springer Science + Business Media)

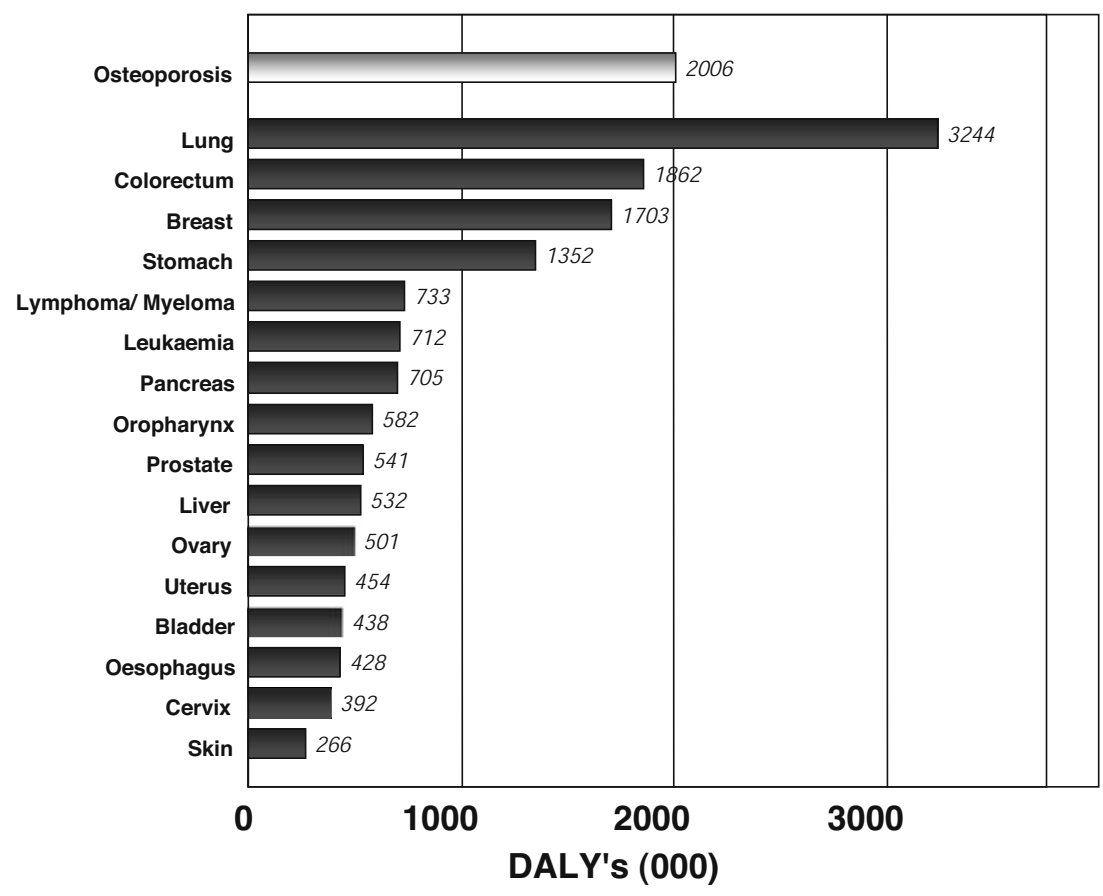


whole skeleton as well as of specific sites, including those most vulnerable to fracture $[8,11,12]$. The term bone mineral content describes the amount of mineral in the specific bone site scanned. This can then be used to derive a value for BMD by dividing the bone mineral content by the area measured. This is, therefore, an areal density $\left(\mathrm{g} / \mathrm{cm}^{2}\right)$ rather than a true volumetric density $\left(\mathrm{g} / \mathrm{cm}^{3}\right)$ since the scan is two-dimensional. Areal BMD accounts for about two-thirds of the variance of bone strength as determined in vitro on isolated bones, such as the vertebral body or proximal femur.

Dual-energy X-ray absorptiometry can also be used to visualise lateral images of the spine from $\mathrm{T} 4$ to $\mathrm{L} 4$ to detect deformities of the vertebral bodies. Vertebral fracture assessment (VFA) may improve fracture risk evaluation, since many patients with vertebral fracture may not have a BMD T-score classified as osteoporosis. This procedure involves less radiation and is less expensive than a conventional X-ray examination. VFA has a sensitivity and specificity of about $90 \%$ for the detection of grade 2 and 3 fractures, according to the semiquantitative method of Genant. Whereas whole body bone, fat and lean mass can also be measured using DXA, these measurements are useful for research, but do not assist in the routine diagnosis or assessment of osteoporosis.

The performance characteristics of many measurement techniques have been well documented [13-15]. For the purpose of risk assessment and for diagnosis, the characteristic of major importance is the ability of a technique to predict fractures. This is traditionally expressed as the increase in the relative risk of fracture per standard deviation unit decrease in bone mineral measurementtermed the gradient of risk.

There are significant differences in the performance of different techniques at different skeletal sites. In addition, the performance depends on the type of fracture that one wishes to predict $[14,16]$. For example, BMD assessments by DXA to predict hip fracture are more predictive when measurements are made at the hip rather than at the spine or forearm (Table 3). For the prediction of hip fracture, the gradient of risk provided by hip BMD is 2.6. In other words, the fracture risk increases 2.6-fold for each SD decrease in hip BMD. Thus, an individual with a Z-score of -3 at the hip would have a $2.6^{3}$ or greater than 15 -fold higher risk than an individual of the same age with a Z- score of 0 . Where the intention is to predict any osteoporotic fracture, the commonly used techniques are comparable: the risk of fracture increases approximately 1.5 -fold for each standard deviation decrease in the measurement. Thus, an individual with a measurement of 3 standard deviations below the average value for age would have a $1.5^{3}$ or greater than 3 -fold higher risk than an individual with an average BMD. Note that the risk of fracture in individuals with an average BMD is lower than the average fracture risk, since BMD is normally distributed in the general population, whereas the risk of fracture increases exponentially with decreasing BMD.

The widespread clinical use of DXA, particularly at the proximal femur and lumbar spine (central DXA), arises from many prospective studies that have documented a strong gradient of risk for fracture prediction. For example, a widely cited meta-analysis [14] indicated that the risk of hip fracture increased 2.6-fold for each standard deviation decrease in BMD at the femoral neck. The gradient of risk is even higher in women at, or just after the menopause [17]. These gradients of risk are higher than those derived using many other techniques, and the use of central DXA predicts other types of fracture with as high a gradient of risk as other competing techniques. The vast amount of information available for central DXA has meant that it has now become the reference standard. The adoption of DXA as a reference standard provides a platform on which the performance characteristics of less well established methodologies can be compared.

The performance characteristics of ultrasound are similar. Most studies suggest that measurements of broadband ultrasound attenuation (BUA) or speed of sound ( $\mathrm{SoS})$ at the heel are associated with a 1.5- to 2-fold increase in risk for each standard deviation decrease in BMD [15]. Comparative studies indicate that these gradients of risk are very similar to those provided by peripheral assessment of BMD at appendicular sites by absorptiometric techniques to predict any osteoporotic fracture [14].

\section{Diagnostic thresholds}

The following four general descriptive categories are given below for adult men and women using measurements of DXA at the femoral neck $[18,19]$.

Table 3 Age-adjusted increase in risk of fracture (with 95\% confidence interval) in women for every 1 SD decrease in bone mineral density (BMD; by absorptiometry) below the mean value for age. (Amended with permission from the BMJ Publishing Group [14])

\begin{tabular}{lllll}
\hline Site of measurement & Forearm fracture & Hip fracture & Vertebral fracture & All fractures \\
\hline Distal radius & $1.7(1.4-2.0)$ & $1.8(1.4-2.2)$ & $1.7(1.4-2.1)$ & $1.4(1.3-1.6)$ \\
Femoral neck & $1.4(1.4-1.6)$ & $2.6(2.0-3.5)$ & $1.8(1.1-2.7)$ & $1.6(1.4-1.8)$ \\
Lumbar spine & $1.5(1.3-1.8)$ & $1.6(1.2-2.2)$ & $2.3(1.9-2.8)$ & $1.5(1.4-1.7)$ \\
\hline
\end{tabular}


1. Normal: a value for BMD that is higher than 1 standard deviation below the young adult female reference mean (T-score greater than or equal to $-1 \mathrm{SD}$ ).

2. Low bone mass (osteopenia): a value for BMD more than 1 standard deviation below the young female adult mean, but less than $2.5 \mathrm{SD}$ below this value (T-score $<-1$ and $>-2.5 \mathrm{SD}$ ).

3. Osteoporosis: a value for BMD $2.5 \mathrm{SD}$ or more below the young female adult mean (T-score less than or equal to $-2.5 \mathrm{SD}$ ).

4. Severe osteoporosis (established osteoporosis): a value for BMD 2.5 SD or more below the young female adult mean in the presence of 1 or more fragility fractures.

The recommended reference range is the NHANES III reference database for femoral neck measurements in women aged 20-29 years [20, 21], as previously recommended by the International Osteoporosis Foundation [22].

These diagnostic criteria for osteoporosis are similar to those previously proposed by the World Health Organization in 1994 [13, 23], but differ by specifying a reference site (the femoral neck), providing a young normal reference range, and by accommodating diagnostic criteria for men.

The original 1994 WHO criteria provided for diagnosis of osteoporosis at the hip, lumbar spine or forearm. Data arising with the development of new measurement techniques applied to many different skeletal sites indicate that the same T-score derived from different sites and techniques yield quite different information on fracture risk The intersite correlations, though of statistical significance, are inadequate for predictive purposes. These considerations have led to the adoption of a reference site [22]. This does not preclude the use of other sites and technologies in clinical practice, though it should be recognised that the information derived from the T-score will differ from that provided by BMD at the femoral neck.

Diagnostic thresholds differ from intervention thresholds for several reasons. First, the fracture risk varies markedly in different populations. For example, in women with a T-score of $-2.5 \mathrm{SD}$, the probability of hip fracture is 5 times greater at the age of 80 years than at the age of 50 years. Other factors that determine intervention thresholds include the presence of clinical risk factors, and high indices of bone turnover. Intervention thresholds will also be determined in part by the cost and benefits of treatment.

\section{Prevalence of osteoporosis}

The prevalence of osteoporosis in Sweden using the WHO criteria is shown for Swedish men and women in Table 4 [24]. Approximately $6 \%$ of men and $21 \%$ of women aged 50-84 years are classified as having osteoporosis. The prevalence of osteoporosis in men over the age of 50 years is 3 times less frequent than in women-comparable to the difference in lifetime risk of an osteoporotic fracture in men and women.

The prevalence of osteoporosis utilising either the total hip or the femoral neck is rather similar in women, suggesting that this site could eventually supplant the use of femoral neck BMD when adequate meta-analyses have delineated the performance of total hip BMD to estimate fracture risk.

Measurement of multiple skeletal sites

A number of guidelines favour the concurrent use of BMD at the proximal femur and at the lumbar spine for patient assessment. Patients are defined as having osteoporosis on the basis of the lower of two T-scores. For example, the International Society for Clinical Densitometry recommends that patients who have a BMD test receive scans of both the lumbar spine and hip $[25,26]$. Patients are characterised as having osteoporosis where the T-score is $-2.5 \mathrm{SD}$ or less at the spine, femoral neck or total hip. The prediction of fracture is, however, not improved by the use of multiple sites [27-29]. Selection of patients on the basis of a minimum value from 2 or more tests will, however, increase the number of patients selected. The same result can be achieved by less stringent criteria for the definition of osteoporosis, by defining osteoporosis, for example, as a T-score of $\leq-2.0 \mathrm{SD}$ rather than $\leq-2.5 \mathrm{SD}$. This would undermine, however, the value of a single diagnostic threshold.

\section{Osteopenia}

It is recommended that diagnostic criteria be reserved for osteoporosis and that osteopenia should not be considered to be a disease category. Provision is still, however, made

Table 4 Prevalence of osteoporosis at the age intervals shown in Sweden using female-derived reference ranges at the femoral neck. (Reprinted from [24], with permission from Elsevier)

\begin{tabular}{llllll}
\hline & \multicolumn{3}{l}{ Men } & & \multicolumn{2}{l}{ Women } \\
\cline { 2 - 3 } \cline { 5 - 6 } $\begin{array}{l}\text { Age range } \\
\text { (years) }\end{array}$ & $\begin{array}{l}\text { \% of } \\
\text { population }\end{array}$ & $\begin{array}{l}\text { Number } \\
\text { affected (000) }\end{array}$ & & $\begin{array}{l}\text { \% of } \\
\text { population }\end{array}$ & $\begin{array}{l}\text { Number } \\
\text { affected (000) }\end{array}$ \\
\hline $50-54$ & 2.5 & 7.0 & 6.3 & 17.0 \\
$55-59$ & 3.5 & 7.6 & & 9.6 & 21.1 \\
$60-64$ & 5.8 & 11.4 & & 14.3 & 30.0 \\
$65-69$ & 7.4 & 14.2 & 20.2 & 43.7 \\
$70-74$ & 7.8 & 14.6 & 27.9 & 63.0 \\
$75-79$ & 10.3 & 13.7 & 37.5 & 68.3 \\
$80-84$ & 16.6 & 14.7 & & 47.2 & 67.8 \\
$50-80$ & 6.3 & 83.2 & 21.2 & 310.9 \\
\hline
\end{tabular}


for the description of osteopenia. This is intended more for descriptive purposes for the epidemiology of osteoporosis rather than as a diagnostic criterion. Also, the identification of osteopenia will capture the majority of individuals who will develop osteoporosis in the next 10 years.

\section{Limitations}

There are a number of limitations in the general application of DXA for diagnosis that should be recognised [30, 31]. The presence of osteomalacia, a complication of poor nutrition in the elderly, will underestimate total bone mass because of decreased mineralisation of bone. Osteoarthrosis or osteoarthritis at the spine or hip are common in the elderly, and contribute to the density measurement, but not necessarily to skeletal strength. Heterogeneity of density due to osteoarthrosis, previous fracture or scoliosis can often be detected on the scan and in some cases excluded from the analysis. Some of these problems can be overcome with adequately trained staff and rigorous quality control. As mentioned, the image is two dimensional and therefore provides an areal BMD rather than a volumetric BMD. The computation of BMD is sensitive to changes in bone size. For example, areal bone density will overestimate volumetric bone density in individuals with large bones. In adults, this error is fortuitously beneficial since larger bones in general have higher strength. Thus, this "error" may improve fracture prediction in adults.

\section{General management}

\section{Mobility and falls}

Immobilisation is a very important cause of bone loss. Immobilised patients may lose as much bone in a week when confined to bed as they would otherwise lose in a year. For this reason immobility should wherever possible be avoided. The amount of weight-bearing exercise that is optimal for skeletal health in patients with osteoporosis is not known, but exercise forms an integral component of management [32]. Physiotherapy is an important component of rehabilitation after fracture. At all times, increased strength may prevent falls by improving confidence and coordination as well as maintaining bone mass by stimulating bone formation and by decreasing bone resorption.

Such measures can be coupled with a programme to reduce the likelihood of falls in those at high risk. Risk factors for falling are shown in Table 5 [33]. Modifiable factors such as the correcting decreased visual acuity, reducing consumption of medication that alters alertness and balance, and improvement of the home environment (slippery floors, obstacles, insufficient light-
Table 5 Risk factors associated with falls. (Adapted from [33], with permission from Elsevier)

\begin{tabular}{ll}
\hline Number & Risk factor \\
\hline 1. & Impaired mobility, disability \\
2. & Impaired gait and balance \\
3. & Neuromuscular or musculoskeletal disorders \\
4. & Age \\
5. & Impaired vision \\
6. & Neurological, heart disorders \\
7. & History of falls \\
8. & Medication \\
9. & Cognitive impairment \\
\hline
\end{tabular}

ing, handrails) are important measures aimed at preventing falls. Although large trials have shown that it is possible to reduce falls [34, 35], randomised studies have not shown any significant decrease in fracture risk. Some randomised trials have shown that wearing hip protectors can markedly reduce hip fracture risk, particularly in the elderly living in nursing homes. A recent meta-analysis of well-conducted randomised controlled trials has, however, cast some doubt on the antifracture efficacy of this preventive measure [36-38].

\section{Nutrition}

There is a high prevalence of calcium, protein and vitamin D insufficiency in the elderly. Vitamin D supplements can reduce the risk of falling provided the daily dose of vitamin $\mathrm{D}$ is greater than $700 \mathrm{IU}$ [39]. Whereas a gradual decline in caloric intake with age can be considered as an appropriate adjustment to the progressive reduction in energy expenditure, the parallel reduction in protein intake may be detrimental for maintaining the integrity and function of several organs or systems, including skeletal muscle and bone. Calcium and vitamin D supplements decrease secondary hyperparathyroidism and reduce the risk of proximal femur fracture, particularly in the elderly living in nursing homes. Intakes of at least $1,000 \mathrm{mg}$ /day of calcium, $800 \mathrm{IU}$ of vitamin D and of $1 \mathrm{~g} / \mathrm{kg}$ body weight of protein can be recommended in the general management of patients with osteoporosis [40].

Sufficient protein intakes are necessary to maintain the function of the musculoskeletal system, but they also decrease the complications that occur after an osteoporotic fracture. Correction of poor protein nutrition in patients with a recent hip fracture has been shown to improve the subsequent clinical course by significantly lowering the rate of complications, such as bedsores, severe anaemia, and intercurrent lung or renal infection. The duration of hospital stay of elderly patients with hip fracture can thus be shortened. [41]. 


\section{Major pharmacological interventions}

The most commonly used agents in Europe are raloxifene, the bisphosphonates alendronate, ibandronate and risedronate, agents derived from parathyroid hormone and strontium ranelate. Until recently, hormone replacement treatment was also widely used. They have all been shown to reduce the risk of vertebral fracture. Some have been shown to also reduce the risk of non-vertebral fractures, in some cases specifically fractures at the hip (Table 6) [42, 43].

\section{Selective estrogen-receptor modulators}

Selective estrogen-receptor modulators (SERMs) are nonsteroidal agents that bind to the oestrogen receptor and act as oestrogen agonists or antagonists, depending on the target tissue. The concept of SERMs was triggered by the observation that tamoxifen, which is an oestrogen antagonist in breast tissue, is a partial agonist on bone, reducing the rate of bone loss in postmenopausal women. Raloxifene is the only SERM available for the prevention and treatment of postmenopausal osteoporosis, but several others are in clinical development. Raloxifene prevents bone loss [44] and reduces the risk of vertebral fractures by $30-50 \%$ in postmenopausal women with low bone mass, and with osteoporosis with or without prior vertebral fractures as shown in the MORE trial [45]. There was no significant reduction of non-vertebral fractures. In women with severe vertebral fractures at baseline (i.e. at highest risk of subsequent fractures) a post hoc analysis showed a significant reduction of nonvertebral fractures [46]. In the MORE study and its placebo-controlled 4-year follow-up (CORE), the only severe (but rare) adverse event was an increase in deep venous thromboembolism. There was a significant and sustained significant decrease in the risk of invasive breast cancer (by about 60\%) [47], which has been subsequently confirmed in two other large cohorts, including the STAR study, which showed a similar breast cancer rate with raloxifene and tamoxifen in high-risk populations [48]. The RUTH study, performed in postmenopausal women at high risk of cardiovascular disease [49] showed that raloxifene had no effect on cardiovascular death, and on the incidence of coronary heart disease and stroke, [50]. In summary, the overall risk benefit ratio of raloxifene is favourable and the drug is approved widely for the prevention and treatment of postmenopausal osteoporosis.

\section{Bisphosphonates}

Bisphosphonates are stable analogues of pyrophosphate characterised by a P-C-P bond. A variety of bisphosphonates has been synthesised, the potency of which depends on the length and structure of the side chain. Bisphosphonates have a strong affinity for bone apatite, both in vitro and in vivo, which is the basis for their clinical use. They are potent inhibitors of bone resorption and produce their effect by reducing the recruitment and activity of osteoclasts and increasing their apoptosis. The potency of bisphosphonates in inhibiting bone resorption varies greatly from compound to compound and ranges 10,000-fold in vitro, so that the doses used clinically also vary. The mechanism of action on osteoclasts includes inhibition of the proton vacuolar adenosine triphosphatase (ATPase) and alteration of the cytoskeleton and the ruffled border. Aminobisphosphonates also inhibit several steps of the mevalonate pathway, thereby modifying the isoprenylation of guanosine triphosphate binding proteins.

Table 6 Antifracture efficacy of the most frequently used treatments for postmenopausal osteoporosis when given with calcium and vitamin D, as derived from randomised controlled trials. (Updated from $[42,43]$ )

\begin{tabular}{|c|c|c|c|c|}
\hline & \multicolumn{2}{|c|}{ Effect on vertebral fracture risk } & \multicolumn{2}{|c|}{ Effect on non-vertebral fracture risk } \\
\hline & Osteoporosis & Established osteoporosis $^{\mathrm{a}}$ & Osteoporosis & Established osteoporosis ${ }^{\mathrm{a}}$ \\
\hline Alendronate & + & + & NA & + (including hip) \\
\hline Risedronate & + & + & NA & + (including hip) \\
\hline Ibandronate & NA & + & NA & $+{ }^{\mathrm{b}}$ \\
\hline Zoledronic acid & + & + & NA & $\mathrm{NA}(+)^{\mathrm{c}}$ \\
\hline HRT & + & + & + & + \\
\hline Raloxifene & + & + & NA & NA \\
\hline Teriparatide and PTH & NA & + & NA & + \\
\hline Strontium ranelate & + & + & +(including hip) & + (including hip) \\
\hline
\end{tabular}

NA: no evidence available

+ : effective drug

${ }^{\mathrm{a}}$ Women with a prior vertebral fracture

${ }^{\mathrm{b}}$ In subsets of patients only (post-hoc analysis)

${ }^{\mathrm{c}}$ Mixed group of patients with or without prevalent vertebral fractures 
Oral bioavailability of bisphosphonates is low, between 1 and $3 \%$ of the dose ingested, and is impaired by food, calcium, iron, coffee, tea and orange juice. Bisphosphonates are quickly cleared from plasma, about $50 \%$ being deposited in bone and the remainder excreted in urine. Their half-life in bone is very prolonged.

Alendronate $70 \mathrm{mg}$ once weekly and risedronate $35 \mathrm{mg}$ once weekly are the most commonly used bisphosphonates worldwide. In the FIT study, alendronate was shown to reduce the incidence of vertebral, wrist and hip fractures by approximately half in women with prevalent vertebral fractures [51-53]. In women without prevalent vertebral fractures, there was no significant decrease in clinical fractures in the overall population, but the reduction was significant in the one-third of patients who had a baseline hip BMD T-score lower than -2.5 SD [54]. Risedronate has been shown in women with prevalent vertebral fractures to reduce the incidence of vertebral and non-vertebral fractures by $40-50 \%$ and $30-36 \%$ respectively $[55,56]$. In a large population of elderly women, risedronate decreased significantly the risk of hip fractures (by $30 \%$ ), an effect that was greater in osteoporotic women aged $70-79$ years $(-40 \%)$, and not significant in women over the age of 80 years without evidence of osteoporosis [57].

Ibandronate given daily $(2.5 \mathrm{mg})$ reduces the risk of vertebral fractures by $50-60 \%$, whereas an effect on nonvertebral fractures was only demonstrated in a post hoc analysis of women with a baseline of BMD T-score below -3 SD [58, 59]. Bridging studies have shown that oral ibandronate $150 \mathrm{mg}$ once monthly is equivalent or superior to daily ibandronate in increasing BMD and decreasing biochemical markers of bone turnover, giving rise to its approval for the treatment of postmenopausal osteoporosis [60]. Similarly, bridging studies comparing intermittent intravenous ibandronate with daily oral treatment has lead to the approval of intravenous ibandronate ( $3 \mathrm{mg}$ ) every 3 months for the treatment of postmenopausal osteoporosis [61].

Based on the result of a phase II study [62], a large phase III trial has been recently completed in over 7,500 postmenopausal osteoporotic patients assessing the efficacy of yearly infusion of zoledronate $5 \mathrm{mg}$ over 3 years. Compared with the placebo group, zoledronate was found to reduce the incidence of vertebral fractures by $70 \%$ and that of hip fractures by $40 \%$ [63], and is now available for the treatment of postmenopausal osteoporosis. Intravenous zoledronate has also been shown to decrease the risk of fracture and attendant mortality when given shortly after a first hip fracture [64].

The overall safety profile of bisphosphonates is favourable. Oral bisphosphonates are associated with mild gastrointestinal disturbances, and some aminobisphosphonates (alendronate and pamidronate) can rarely cause oesophagitis. Intravenous aminobisphosphonates can induce a transient acute phase reaction with fever, bone and muscle pain that ameliorates or disappears after subsequent courses. Osteonecrosis of the jaw has been described in cancer patients receiving high doses of intravenous pamidronate or zoledronate. The incidence in osteoporotic patients treated with oral and intravenous bisphosphonates appears to be extremely low (in the order of $1 / 100,000$ cases), and its causal relationship with bisphosphonate therapy has not been established.

\section{Peptides of the parathyroid hormone family}

The continuous endogenous production of parathyroid hormone (PTH), as seen in primary or secondary hyperparathyroidism, or its exogenous administration, can lead to deleterious consequences for the skeleton, particularly on cortical bone. However, intermittent administration of PTH (e.g. with daily subcutaneous injections) results in an increase in the number and activity of osteoblasts, leading to an increase in bone mass and in an improvement in skeletal architecture at both cancellous and cortical skeletal sites.

The intact molecule (amino acids 1-84) and the 1-34 $\mathrm{N}$-terminal fragment (teriparatide) are used for the management of osteoporosis. Based on their respective molecular weights, the equivalent dose of the teriparatide, relative to the $1-84$ molecule is $40 \%$ (i.e. 20 and $40 \mu \mathrm{g}$ of teriparatide are equivalent to 50 and $100 \mu \mathrm{g}$ of $1-84 \mathrm{PTH}$ respectively).

Treatment with either agent has been shown to reduce significantly the risk of vertebral fractures, whereas teriparatide has been shown to have an effect also on non-vertebral fractures. The recommended doses are respectively $20 \mu \mathrm{g}$ of teriparatide and $100 \mu \mathrm{g}$ of PTH (1-84) daily, given as a subcutaneous injection [65, 66].

Treatment with PTH has been studied when given for 18 to 24 months and beneficial effects on non-vertebral fractures with teriparatide have been shown to persist for up to 30 months after stopping teriparatide. [67].

The most common reported adverse events in patients treated with PTH or teriparatide are nausea, pain in the limbs, headache and dizziness. In normocalcaemic patients, slight and transient elevations of serum calcium concentrations have been observed following the injection of PTH or teriparatide. Serum calcium concentrations reach a maximum between 4 and $6 \mathrm{~h}$ and return to baseline 16$24 \mathrm{~h}$ after each dose. The change is small and routine monitoring of serum calcium during therapy is not required. PTH and teriparatide may cause small increases in urine calcium excretion, but the incidence of hypercalciuria does not differ from that in placebo-treated patients. However, these agents should be used with caution in patients with active or recent urolithiasis because of their potential to exacerbate the disorder. Isolated episodes of transient orthostatic hypotension are also reported. They typically 
resolve within minutes to a few hours, and do not preclude continued treatment.

The use of peptides of the PTH family is contra-indicated in conditions characterised by abnormally increased bone turnover (e.g. pre-existing hypercalcaemia, metabolic bone diseases other than primary osteoporosis, including hyperparathyroidism and Paget's disease of the bone, unexplained elevation of alkaline phosphatase, prior external beam or implant radiation therapy to the skeleton or in patients with skeletal malignancies or bone metastasis). Severe renal impairment is also a contra-indication. Studies in rats have indicated an increased incidence of osteosarcoma, with longterm administration of very high doses of teriparatide from the time of weaning. These findings appear to have not been considered relevant for patients treated with very much smaller doses of teriparatide.

\section{Strontium ranelate}

Strontium ranelate is a recently registered agent that is marketed for the treatment of postmenopausal osteoporosis, to reduce the risk of vertebral and hip fractures. There is some evidence that strontium ranelate both inhibits bone resorption and stimulates bone formation, suggesting that the agent may uncouple the bone remodelling process when used in the treatment of osteoporosis. Studies conducted for up to 5 years have shown the fracture efficacy of strontium ranelate, at spinal and non-vertebral sites, in a wide range of patients, from osteopenia sufferers to women over the age of 80 years, including osteoporotic patients with or without a prior vertebral fracture. Reduction in hip fracture rates has also been shown in women over the age of 74 years with low bone density at the femoral neck. The decrease in fracture rates observed with strontium ranelate is of similar magnitude to that described for oral bisphosphonates $[68,69]$.

The recommended daily dose is one $2-\mathrm{g}$ sachet once daily by mouth. The absorption of strontium ranelate is reduced by food, milk and its derivative products and the drug should be administered, therefore, between meals. Ideally, it should be taken at bed-time, preferably at least two hours after eating. No dosage adjustment is required in relation to age or in patients with mild to moderate renal impairment (creatinine clearance 30-70 $\mathrm{ml} / \mathrm{min}$ ). Strontium ranelate is not recommended for patients with severe renal impairment (creatinine clearance below $30 \mathrm{ml} / \mathrm{min}$ ).

Adverse events observed with strontium ranelate are usually mild and transient. The most common adverse events are nausea and diarrhoea, which are generally reported at the beginning of treatment and usually disappear after the third month of treatment).

An increase in the incidence of venous thromboembolism (VTE; relative risk $1.42 ; \mathrm{CI}=1.02,1.98$ ) has been reported when pooling all phase III studies in osteoporosis. A causal relationship between VTE and the use of strontium ranelate has not been established and regulatory authorities have not considered a history of VTE as a contra-indication to the use of strontium ranelate. However, strontium ranelate should be used with caution in patients at increased risk of VTE, including those with a past history. When treating patients with an increased risk of developing risk of VTE, particular attention should be given to possible signs and symptoms of VTE and appropriate preventive measures taken.

The effects of the major pharmacological interventions on vertebral and hip fracture risk are summarised in Table 7.

\section{Combination and sequential treatments}

These treatment regimens include the concomitant or sequential use of compounds sharing the same mode of action (e.g. two or more inhibitors of bone resorption) or agents with differing activities (e.g. an inhibitor of resorption plus an anabolic agent). The hope that synergies might be found by combination treatments has not yet been realised.

Most of the current findings suggest that the combination of two inhibitors of bone resorption results in a more pronounced decrease in bone resorption that induces a greater increase in BMD than either agent alone. Whether this results in a better effect on fracture risk has not been adequately addressed. None of the published trials has been designed and powered to detect differences in fracture rates between treatment groups [70].

If low doses of hormone replacement treatment (HRT) are used for a limited period of time for the management of climacteric symptoms, concomitant use of bisphosphonates may provide an appropriate reduction in bone turnover that may not be achieved with low doses of HRT alone. The combination of SERMs and bisphosphonates does not appear to be deleterious for bone, but the use of the combination remains questionable in terms of fracture reduction and from a pharmaco-economic perspective.

Patients pre-treated with inhibitors of bone resorption, who have not achieved a full therapeutic response, are good candidates for treatment with anabolic agents. The increase in bone turnover that follows the introduction of teriparatide in patients treated with an anti-resorptive agent is similar to that observed in treatment-naïve patients as is the pattern of response in BMD, with the exception of a 6-month delay in the increase in spinal and hip BMD in patients previously exposed to alendronate [71].

An important question is whether the combination of an anti-resorptive agent and an anabolic drug, such as PTH, would provide a therapeutic advantage by exploiting the different mechanisms of action on bone, and thereby 
Table 7 Study details and antifracture efficacy (relative risk [RR] and 95\% confidence intervals [CI]) of the major pharmacological treatments used for postmenopausal osteoporosis when given with calcium and vitamin D, as derived from randomised controlled trials

\begin{tabular}{|c|c|c|c|c|c|c|c|}
\hline \multirow[t]{2}{*}{ Intervention } & \multirow[t]{2}{*}{ Study } & \multirow[t]{2}{*}{ Entry criteria } & \multirow[t]{2}{*}{$\begin{array}{l}\text { Mean age } \\
\text { (years) }\end{array}$} & \multirow[t]{2}{*}{$\begin{array}{l}\text { Number of } \\
\text { patients } \\
\text { randomised }\end{array}$} & \multicolumn{2}{|c|}{$\begin{array}{l}\text { Fracture } \\
\text { incidence } \\
\text { (percentage over }^{\text {(p years) }}{ }^{\mathrm{d}}\end{array}$} & \multirow[t]{2}{*}{$\mathrm{RR}(95 \% \mathrm{CI})$} \\
\hline & & & & & Placebo & Drug & \\
\hline \multicolumn{8}{|c|}{ Vertebral fracture (high-risk population) } \\
\hline Alendronate $5-10 \mathrm{mg}$ & {$[51]$} & Vertebral fractures, $\mathrm{BMD} \leq 0.68 \mathrm{~g} / \mathrm{m}^{2}$ & 71 & 2,027 & 15.0 & 8.0 & $0.53(0.41-0.68)$ \\
\hline Risedronate $5 \mathrm{mg}$ & {$[55]$} & $\begin{array}{l}2 \text { vertebral fractures or } 1 \text { vertebral } \\
\text { fracture and T-score } \leq-2.0\end{array}$ & 69 & 2,458 & 16.3 & 11.3 & $0.59(0.43-0.82)$ \\
\hline Risedronate $5 \mathrm{mg}$ & {$[56]$} & $\begin{array}{l}2 \text { or more vertebral fractures - no } \\
\text { BMD entry criteria }\end{array}$ & 71 & 1,226 & 29.0 & 18.0 & $0.51(0.36-0.73)$ \\
\hline Raloxifene $60 \mathrm{mg}$ & {$[45]$} & $\begin{array}{l}\text { Vertebral fractures - no BMD } \\
\text { entry criteria }\end{array}$ & 66 & 7,705 & 21.2 & 14.7 & $0.70(0.60-0.90)$ \\
\hline Teriparatide $20 \mu \mathrm{g}^{\mathrm{a}}$ & {$[65]$} & $\begin{array}{l}\text { Vertebral fractures and FN or LS } \\
\text { T-score } \leq-1 \text { if less than } 2 \text { moderate } \\
\text { fractures }\end{array}$ & 69 & 1,637 & 14.0 & 5.0 & $0.35(0.22-0.55)$ \\
\hline Ibandronate $2.5 \mathrm{mg}$ & {$[58]$} & $\begin{array}{l}\text { Vertebral fractures and LS }-5< \\
\text { T-score } \leq-2.0\end{array}$ & 69 & 2,946 & 9.6 & 4.7 & $0.38(0.25-0.59)$ \\
\hline Ibandronate $20 \mathrm{mg}$ & {$[59]$} & $\begin{array}{l}\text { Vertebral fractures and } \mathrm{LS}-5< \\
\text { T-score } \leq-2.0\end{array}$ & 70 & 708 & 9.6 & 4.9 & $0.50(0.34-0.74)$ \\
\hline Strontium ranelate $2 \mathrm{~g}$ & {$[68]$} & $\begin{array}{l}\text { Vertebral fractures, LS BMD } \leq \\
0.840 \mathrm{~g} / \mathrm{m}^{2}\end{array}$ & 69 & 1,649 & 32.8 & 20.9 & $0.59(0.48-0.73)$ \\
\hline Zoledronic acid $5 \mathrm{mg}$ & {$[63]$} & $\begin{array}{l}\text { FN T score } \leq-2.5, \pm \text { vertebral fracture, } \\
\text { or T-score } \leq-1.5 \text { and } 2+\text { mild or } 1 \\
\text { moderate vertebral fracture }\end{array}$ & 73 & 7,765 & 10.9 & 3.3 & $0.30(0.24-0.38)$ \\
\hline \multicolumn{8}{|c|}{ Vertebral fracture (low-risk population) } \\
\hline Alendronate $5-10 \mathrm{mg}^{\mathrm{b}}$ & {$[54]$} & FN T-score $\leq-2$ & 68 & 4,432 & 3.8 & 2.1 & $0.56(0.39-0.80)$ \\
\hline Alendronate $5-10 \mathrm{mg}^{\mathrm{b}}$ & {$[54]$} & Subgroup of women, T-score $<2.5$ & NA & 1,631 & 4.0 & 2.0 & $0.50(0.31-0.82)$ \\
\hline Raloxifene $60 \mathrm{mg}$ & {$[45]$} & $\begin{array}{l}\text { FN or LS T-score } \leq-2.5, \pm \\
\text { vertebral fractures }\end{array}$ & 66 & 7,705 & 4.5 & 2.3 & $0.50(0.40-0.80)$ \\
\hline \multicolumn{8}{|l|}{ Hip fracture } \\
\hline Alendronate $5-10 \mathrm{mg}$ & {$[51]$} & $\begin{array}{l}\text { Vertebral fractures with } \\
\mathrm{BMD} \leq 0.68 \mathrm{~g} / \mathrm{m}^{2}\end{array}$ & 71 & 2,027 & 2.2 & 1.1 & $0.49(0.23-0.99)$ \\
\hline Alendronate $5-10 \mathrm{mg}^{\mathrm{b}}$ & [54] & FN T-score $\leq-2^{c}$ & 68 & 4,432 & 0.8 & 0.7 & $0.79(0.43-1.44)$ \\
\hline Alendronate $5-10 \mathrm{mg}^{\mathrm{b}}$ & {$[54]$} & $\begin{array}{l}\text { FN T-score } \leq-2.5^{\mathrm{c}} \\
\text { (subgroup analysis) }\end{array}$ & NA & 1,631 & 1.6 & 0.7 & $0.44(0.18-1.97)$ \\
\hline $\begin{array}{l}\text { Risedronate } 2.5 \\
\text { and } 5 \mathrm{mg}\end{array}$ & {$[57]$} & $\begin{array}{l}\text { T-score }<-3^{\mathrm{c}} \text { or }<-2^{\mathrm{c}} \text { and } \geq 1 \\
\text { non-skeletal risk factor for hip } \\
\text { fracture (subgroup analysis osteoporotic } \\
\text { patients } 70-79 \text { years) }\end{array}$ & 77 & 9,331 & 3.2 & 1.9 & $0.60(0.40-0.90)$ \\
\hline $\begin{array}{l}\text { Raloxifene } 60 \text { and } \\
120 \mathrm{mg}\end{array}$ & {$[45]$} & $\begin{array}{l}\text { FN or LS T-score } \leq-2.5, \pm \\
\text { vertebral fractures }\end{array}$ & 66 & 7,705 & 0.7 & 0.8 & $1.10(0.60-1.90)$ \\
\hline Strontium ranelate $2 \mathrm{~g}$ & [69] & $\begin{array}{l}\text { Osteoporosis }(\mathrm{T} \text {-score }<-2.5) \text { with } \\
\text { or without prior fracture }\end{array}$ & 77 & 4,932 & 3.4 & 2.9 & $0.85(0.61-1.19)$ \\
\hline Strontium ranelate $2 \mathrm{~g}$ & [69] & $\begin{array}{l}\text { Age } \geq 74 \text { with T-score } \leq-2.4^{\mathrm{c}} \\
\quad \text { (subgroup analysis) }\end{array}$ & 80 & 1,977 & 6.4 & 4.3 & $\begin{array}{l}0.64(0.412- \\
0.997)\end{array}$ \\
\hline Zoledronic acid $5 \mathrm{mg}$ & {$[63]$} & $\begin{array}{l}\text { FN T score } \leq-2.5 \text { or less, } \pm \text { vertebral } \\
\text { fracture, or T-score } \leq-1.5 \text { and } 2+ \\
\text { mild or } 1 \text { moderate vertebral fracture }\end{array}$ & 73 & 7,765 & 1.4 & 2.5 & $0.59(0.42-0.83)$ \\
\hline
\end{tabular}

FN: femoral neck; LS: lumbar spine: NA: not available

a 20 -month study

b 4 .2-year study

${ }^{\mathrm{c}} \mathrm{BMD}$ adjusted to NHANES population

${ }^{\mathrm{d}}$ Except where indicated in column 1 
optimise the beneficial effects on fracture. When assigning patients to daily treatment with PTH $(1-84,100 \mu \mathrm{g} /$ day $)$ alone, alendronate $(10 \mathrm{mg} /$ day $)$ alone, or both, volumetric density of the trabecular bone at the spine increased substantially in all groups, but the increase in the PTH alone group was about twice that found in either of the other groups. Thus, there was no evidence of synergy between PTH and alendronate [72]. The authors considered that the changes in the volumetric density of trabecular bone, the cortical volume at the hip (significantly increased in the PTH group, but not in the other treatment groups) suggest that the concurrent use of alendronate may reduce the anabolic effects of PTH. A similar conclusion was reached in men, in that alendronate impaired the effects of PTH to increase BMD at the lumbar spine and femoral neck. These results suggest that, if therapy with PTH is contemplated, it should be used alone and not with alendronate [73]. Whether this can be extrapolated to other bisphosphonates or other anti-resorptive agents remains unclear. Notwithstanding, some preliminary studies suggest that SERMs (raloxifene) or other bisphosphonates (risedronate) may not reduce the anabolic effects of PTH to the same extent [74]. The apparent absence of the synergistic effect of PTH and alendronate should not obscure the potential benefit of using an inhibitor of resorption after treatment with PTH. Indeed, there are data that suggest that the administration of an inhibitor of resorption (bisphosphonate or SERM) after treatment with PTH maintains or even potentiates the skeletal benefit observed during PTH treatment [75].

\section{Other pharmacological interventions}

\section{Calcitonin}

Calcitonin is an endogenous polypeptide hormone that inhibits osteoclastic bone resorption [76]. Salmon calcitonin is approximately $40-50$ times more potent than human calcitonin, and the majority of clinical trials have been performed with salmon calcitonin [77]. For clinical use it can be administered either by injection or nasal application, which provides a biological activity of $25-50 \%$ compared with the injectable formulation (200 IU nasal calcitonin would be equivalent to $50 \mathrm{IU}$ of the injectable formulation).

Calcitonin modestly increases BMD at the lumbar spine and forearm $[53,78]$. Calcitonin likely reduces the risk of vertebral fracture; however, the magnitude of the impact on these fractures remains questionable [53, 79]. An effect on non-vertebral fractures remains equivocal $[79,80]$. In addition, calcitonin may have an analgesic effect in women with acute vertebral fracture, which appears to be independent of its effect on osteoclastic resorption [77].
In conclusion, the drawbacks of repeated injections and the high costs of the nasal formulation preclude the longterm use of calcitonin as a first-line treatment of osteoporosis. Analgesic properties may, however, be an interesting option for acute pain following a spinal fracture.

\section{Hormone replacement therapy}

Oestrogens reduce the accelerated bone turnover induced by the menopause, and prevent bone loss at all skeletal sites regardless of age and duration of therapy. Results from observational studies and randomised placebo-controlled trials have shown that oestrogens decrease the risk of vertebral and non-vertebral fractures (including hip fracture) by about $30 \%$, regardless of baseline BMD [42, 81, 82]. When hormone replacement therapy (HRT) is stopped, bone loss resumes at the same rate as after the menopause, but fracture protection may persist arguably for several years $[83,84]$.

The Women's Health Initiative (WHI) suggests, however, that the long-term risks of HRT outweigh the benefits. In this large cohort of postmenopausal women in their $60 \mathrm{~s}$, the combined use of conjugated oestrogen and medroxyprogesterone acetate was associated with a $30 \%$ increased risk of coronary heart disease (CHD) and breast cancer, and with a $40 \%$ increase in stroke [85-87]. There was also a slight increase in the risk of dementia [88], and no clinically meaningful effect on health-related quality of life such as sleep disturbance or vasomotor symptoms [89]. In a subsequent analysis, the increase in breast cancer risk was much less in women not previously exposed to HRT [87]. In hysterectomised women receiving conjugated oestrogen alone, there was also a significant increase in stroke, but not in CHD and breast cancer, suggesting a deleterious effect of medroxyprogesterone acetate [90]. Whether the benefits of HRT would outweigh the risks with other oestrogen and progestin and in younger postmenopausal women is debated, but so far there has been no placebo-controlled study showing the long-term safety of such alternatives. In most countries, HRT is only recommended for climacteric symptoms, at a dose as small as possible and for a limited period of time. Thus, HRT is no longer recommended as a first-line treatment for the prevention and treatment of osteoporosis.

\section{Etidronate}

Etidronate is a weak bisphosphonate that has been shown to reduce vertebral fractures over 2 years, but not subsequently, with no significant effect on non-vertebral fractures [91]. Thus, etidronate is not recommended as a first-line therapy for osteoporosis in most European countries. 
Vitamin D derivatives

Alfacalcidol is a synthetic analogue of the vitamin D metabolite calcitriol (1,25-dihydroxyvitamin $\left.\mathrm{D}_{3}\right)$ and it is metabolised to calcitriol by its 25 -hydroxylation in the liver. It is somewhat less potent than calcitriol. Both alfacalcidol and calcitriol are used in some countries for the treatment of osteoporosis. Several but not all studies show decreases in vertebral fracture risk [92-94]. The effects on BMD have been less extensively studied.

A few reports have suggested that alfacalcidol and calcitriol exert a direct action on muscle strength and decrease the likelihood of falling in elderly subjects [95].

The major problem with the use of the vitamin D derivatives is the risk of hypercalcaemia and hypercalciuria. Adverse effects of prolonged hypercalcaemia include impairment of renal function and nephrocalcinosis. The narrow therapeutic window demands the frequent surveillance of serum and possibly urine calcium in patients exposed to these agents. Calcium supplementation of the diet should be avoided or used with care.

\section{Clodronate}

Clodronate is a relatively weak bisphosphonate, but has been shown to decrease the risk of vertebral and nonvertebral fractures in randomised controlled studies [91, 96]. It is widely available for the treatment of neoplastic bone disease, but licensed for use in osteoporosis in only a few countries.

\section{Adherence and monitoring of treatment}

\section{Adherence to treatment}

When discussing adherence there is a need to define the terminology [97], since a wide variety of definitions are used in the literature.

1. Adherence is a general term encompassing the aspects mentioned below.

2. Persistence describes for how long the medication is taken. Persistence could be expressed as number of days until drop-out or the proportion of the cohort still on the medication after a given time since first prescription. Non-persistence is assumed to be the same as discontinuation if a treatment gap is longer than a set number of days.

3. Compliance denotes the proximity to the treatment recommendation as given in the official product information (SPC). It is often simplified to mean the number of doses taken divided by the number of prescribed doses. This simplification does not include some important aspects of compliance, such as taking medication with food (for the oral bisphosphonates), at the correct time of the day, too large doses to compensate for forgotten doses, pill dumping, etc.

4. Primary non-adherence is when the patient is prescribed a drug and then never fills the prescription.

Non-adherence to medical therapy is a widespread public health problem. It is estimated that only half of the patients comply with long-term therapy, of whom a substantial minority do not even redeem their prescription.

Poor adherence to treatment is common in osteopenia and osteoporosis. Overcoming non-adherence presents particular challenges in asymptomatic bone diseases and other chronic, asymptomatic conditions. In such settings, the level of perceived threat to health does not motivate the patient to adhere to therapy. In addition, risk of nonadherence with any therapy increases with increased duration of treatment [98].

Poor adherence to medication is associated with adverse effects on outcomes in osteoporosis or osteopenia, and nonadherent patients have smaller decreases in rates of bone turnover, smaller gains in BMD and a significantly greater risk of fracture [99].

Improving adherence to osteoporosis therapy requires effective patient/provider communication and close patient monitoring for the early identification of declining adherence. Patients' belief in a medication contributes to better adherence and can be improved by firmly associating treatment with expected benefits such as reduced risk of fracture and thereby an improved quality of life. Patients may be encouraged to adhere when presented with measurements of biochemical markers of bone turnover or their BMD results together with an explanation of how these measures relate to risk reduction. Another primary component of improving adherence is to use simplified or user-friendly treatment programs [100].

It should be noted that inadequate adherence can also take the form of improper drug administration, even when doses are not missed. An example is the malabsorption of oral bisphosphonates when taken with food. Such nonadherence poses the potential problems of decreased drug absorption and increased risk of adverse effects [101].

\section{Monitoring of treatment with densitometry}

The goal of drug therapy in a patient with osteoporosis is to significantly increase bone strength, in order to decrease the risk of fracture. In untreated men and women, BMD is one of the major determinants of bone strength, and low BMD is an important predictor of fracture. Whether the long-term anti-fracture efficacy of anti-osteoporotic drugs will depend 
on the extent to which treatment can increase or maintain BMD is controversial. Meta-regressions, based on summary statistics demonstrate a stronger correlation between the change in BMD and fracture risk reduction than results based on the individual patient data $[102,103]$.

Whereas $16 \%$ of vertebral fracture risk reduction after treatment with alendronate was attributed to an increase in BMD at the lumbar spine [104], larger increases in BMD at both the spine and hip, observed with alendronate were associated with greater reductions in the risk of non-vertebral fractures. However, for patients treated with risedronate or raloxifene, changes in BMD predict even more poorly the degree of reduction in vertebral (raloxifene) or non-vertebral (risedronate) fractures. Twelve percent and $7 \%$ of the effects of risedronate to reduce non-vertebral fractures were attributed to changes in the spine and femoral neck BMD respectively [105]. For raloxifene, the percentage changes in BMD accounted for $4 \%$ of the observed vertebral fracture risk reduction [106].

For bone-forming agents, increases in BMD account for approximately one-third of the vertebral fracture risk reduction with teriparatide [107]. Preliminary data suggest that a larger proportion (up to 74\%) of the anti-fracture efficacy of strontium ranelate might be explained by changes in total hip or femoral neck BMD [108]. Further data are needed on the role of BMD monitoring patients treated with bone-forming agents, but appears to be of greater value than their use with inhibitors of bone resorption.

Monitoring of treatment with biochemical markers of bone turnover

Several markers have been developed over the past 20 years that reflect the overall rate of bone formation and/or bone resorption. Most are immunoassays using antibodies that recognise specifically a component of bone matrix (i.e. type I collagen or non-collagenous proteins) that is released in the bloodstream during the process of either osteoblastic bone formation or osteoclastic resorption. Other assays recognise enzymatic activity associated with the osteoblast (bone alkaline phosphatase) or the osteoclast (tartrateresistant acid phosphatase). The most informative ones for the investigation of osteoporosis are osteocalcin and procollagen I N-terminal extension peptide (P1NP) for assessing bone formation, and type I collagen - and Ctelopeptide breakdown products (especially serum CTX) to assess bone resorption [109, 110].

Antiresorptive therapies such as calcitonin, oestrogen, SERMs and bisphosphonates induce a significant decrease in bone markers that return to the premenopausal range within 3-6 months for the resorption markers and within 69 months for markers of formation. The decrease in markers of bone turnover seen with alendronate or oestrogen is dose-related and correlates with the long-term (2-3 years) increase in BMD at the spine and hip [111]. More importantly, a significant association has been reported between the short-term decrease and the absolute level of markers of bone turnover with the use of antiresorptive agents (raloxifene and bisphosphonates) on the one hand, and the magnitude of the reduction of the risk of vertebral and non-vertebral fractures on the other hand [112-114]. In addition, a large prospective study suggests that the use of markers of bone turnover in the monitoring of bisphosphonate therapy is associated with a greater persistence with therapy than in those not monitored [115]. Thus, measurement of markers of bone turnover after a few months of treatment may provide useful information on efficacy and improve persistence. During bone-forming therapy with teriparatide, serum P1NP increases 2- to 3-fold within 1-3 months, a change that correlates with the subsequent increase in BMD $[116,117]$. There are no data relating changes in bone turnover induced with teriparatide to the subsequent reduction of fracture risk. Changes in markers of bone turnover with strontium ranelate are of small magnitude and are unlikely to be clinically useful for the monitoring of treatment [68].

\section{Assessment of fracture risk}

The increasing prevalence and awareness of osteoporosis, together with the development of treatments of proven efficacy, will increase the demand for the management of patients with osteoporosis. This in turn will require widespread facilities for the assessment of osteoporosis. Measurements of bone mineral are a central component of any provision, since osteoporosis is defined in terms of BMD and micro-architectural deterioration of bone tissue. Presently, there are no satisfactory clinical tools available to assess bone quality independently of bone density, so that for practical purposes, the assessment of osteoporosis depends upon the measurement of skeletal mass, as assessed by measurements of BMD [13].

The clinical significance of osteoporosis is the fractures that arise with their attendant morbidity and mortality. For this reason attention has focussed on the identification of patients at high risk of fracture rather than the identification of men and women with osteoporosis [118]. Although bone mass is an important component of the risk of fracture, other abnormalities occur in the skeleton that contribute to fragility. In addition, a variety of non-skeletal factors, such as the liability to fall and force of impact, contribute to fracture risk. Since BMD forms but one component of fracture risk, accurate assessment of fracture risk should ideally take into account other readily measured indices of fracture risk that add information to that provided by BMD. 
Bone mineral density

The use of bone mass measurements for prognosis depends upon accuracy. Accuracy in this context is the ability of the measurement to predict fracture. In general, all absorptiometric techniques have high specificity but low sensitivity, which varies with the cut-off chosen to designate high risk. Many cross-sectional prospective population studies indicate that the risk of fracture increases by a factor of 1.5 to 3.0 for each standard deviation decrease in BMD (see Table 3) [14]. The ability of BMD to predict fracture is comparable to the use of blood pressure to predict stroke, and significantly better than serum cholesterol to predict myocardial infarction [13].

Despite these performance characteristics, it should be recognised that, just because BMD is normal, there is no guarantee that a fracture will not occur-only that the risk is decreased. Conversely, if BMD is within the osteoporotic range, then fractures are more likely, but not invariable. At the age of 50 years, the proportion of women with osteoporosis who will fracture their hip, spine or forearm or proximal humerus in the next 10 years (i.e. positive predictive value) is approximately $45 \%$. The detection rate for these fractures (sensitivity) is, however, low and $96 \%$ of fractures at the spine, hip, forearm or proximal humerus would occur in women without osteoporosis [119]. The low sensitivity is one of the reasons why widespread population-based screening with BMD is not widely recommended in women at the time of the menopause.

Age

The performance characteristics of the test can, however, be improved by the concurrent consideration of risk factors that operate independently of BMD. Perhaps the best example is age. The same T-score with the same technique at any one site has a different significance at different ages. For any BMD, fracture risk is much higher in the elderly than in the young [120]. This is because age contributes to risk independently of BMD. At the threshold for osteoporosis (T-score $=-2.5$ $\mathrm{SD}$ ), the probability of hip fracture ranges from 1.4 to $10.5 \%$ in men and women from Sweden depending on age (Table 8) [121]. Thus, the consideration of age and BMD together increases the range of risk that can be identified.

There are, however, a large number of additional risk factors that provide information on fracture risk independently of both age and BMD.

Other clinical risk factors

A large number of additional risk factors for fracture have been identified [122-124]. For the purposes of risk assessment, interest lies in those factors that contribute
Table 8 Ten-year probability of hip fracture (percentage) in Swedish women according to age in the general population and by BMD at the femoral neck. (Reprinted from [121], with kind permission from Springer Science + Business Media)

\begin{tabular}{llllll}
\hline $\begin{array}{l}\text { Age } \\
\text { (years) }\end{array}$ & Population & $\begin{array}{l}\text { T-score }= \\
-1\end{array}$ & $\begin{array}{l}\text { T-score } \leq \\
-1\end{array}$ & $\begin{array}{l}\text { T-score } \\
-2.5\end{array}$ & $\begin{array}{l}\text { T-score } \leq \\
-2.5\end{array}$ \\
\hline 45 & 0.4 & 0.4 & 0.8 & 1.4 & 2.2 \\
50 & 0.6 & 0.5 & 1.1 & 1.7 & 2.9 \\
55 & 1.2 & 0.7 & 2.0 & 2.9 & 5.1 \\
60 & 2.3 & 1.1 & 3.3 & 4.4 & 7.8 \\
65 & 3.9 & 1.5 & 5.0 & 5.9 & 10.9 \\
70 & 7.3 & 2.0 & 8.3 & 8.8 & 16.7 \\
75 & 11.7 & 2.3 & 11.8 & 11.1 & 21.5 \\
80 & 15.5 & 2.5 & 14.6 & 11.5 & 23.8 \\
85 & 16.1 & 2.1 & 14.7 & 10.0 & 21.9 \\
\hline
\end{tabular}

significantly to fracture risk over and above that provided by BMD measurements or age [125]. A caveat is that some risk factors identify a risk that is not amenable to particular treatments, so that the relationship between absolute probability of fracture and reversible risk is important. Liability to falls is an appropriate example where the risk of fracture is high, but treatment with agents affecting bone metabolism may arguably have little or no effect on risk.

Over the past few years a series of meta-analyses has been undertaken to identify clinical risk factors that could be used in case finding strategies with or without the use of BMD. These are summarised below and their predictive value for hip fracture risk shown in Table 9 [126].

1. Low body mass index (BMI). A low BMI is a significant risk factor for hip fracture. Thus, the risk is nearly two-fold increased comparing individuals with a BMI of $25 \mathrm{~kg} / \mathrm{m}^{2}$ and $20 \mathrm{~kg} / \mathrm{m}^{2}$ (see Table 9). It is important to note that the comparison of 25 versus $30 \mathrm{~kg} / \mathrm{m}^{2}$ is not associated with a halving of risk, i.e. leanness is more of a risk factor rather than obesity being a protective factor. It is also important to note that the value of BMI in predicting fractures is very much diminished when adjusted for BMD [127].

2. Many studies indicate that a history of fragility fracture is an important risk factor for further fracture $[17,128]$. Fracture risk is approximately doubled in the presence of a prior fracture. The increase in risk is even more marked for a vertebral fracture following a previous spine fracture. The risks are in part independent of BMD. In general, adjustment for BMD would decrease the relative risk by $10-20 \%$ (see Table 3).

3. A family history of fragility fractures is a significant risk factor that is largely independent of BMD [129]. A family history of hip fracture is a stronger risk factor than a family history of other osteoporotic fractures and is independent of BMD. 
Table 9 Risk ratio (RR) for hip fracture and $95 \%$ confidence intervals $(\mathrm{CI})$ associated with risk factors adjusted for age, with and without adjustment for BMD. (Reprinted from [126], with kind permission from Springer Science + Business Media)

\begin{tabular}{|c|c|c|c|c|}
\hline \multirow[b]{2}{*}{ Risk indicator } & \multicolumn{2}{|c|}{ Without BMD } & \multicolumn{2}{|c|}{ With BMD } \\
\hline & RR & $95 \% \mathrm{CI}$ & $\mathrm{RR}$ & $95 \% \mathrm{CI}$ \\
\hline Body mass index $\left(20 \mathrm{v} 25 \mathrm{~kg} / \mathrm{m}^{2}\right)$ & 1.95 & $1.71-2.22$ & 1.42 & $1.23-1.65$ \\
\hline$\left(30 \mathrm{v} 25 \mathrm{~kg} / \mathrm{m}^{2}\right)$ & 0.83 & $0.69-0.99$ & 1.00 & $0.82-1.21$ \\
\hline Prior fracture after 50 years & 1.85 & $1.58-2.17$ & 1.62 & $1.30-2.01$ \\
\hline Parental history of hip fracture & 2.27 & $1.47-33.49$ & 2.28 & $1.48-3.51$ \\
\hline Current smoking & 1.84 & $1.52-2.22$ & 1.60 & $1.27-2.02$ \\
\hline Ever use of systemic glucocorticoids & 2.31 & $1.67-3.20$ & 2.25 & $1.60-3.15$ \\
\hline Alcohol intake $>2$ units daily & 1.68 & $1.19-2.36$ & 1.70 & $1.20-2.42$ \\
\hline Rheumatoid arthritis & 1.95 & $1.11-3.42$ & 1.73 & $0.94-3.20$ \\
\hline
\end{tabular}

4. Cigarette smoking is a risk factor that is in part dependent on BMD [130].

5. Glucocorticoids are an important cause of osteoporosis and fractures [131]. The fracture risk conferred by the use of glucocorticoids is, however, not solely dependent upon bone loss and BMD independent risks have been identified [132].

6. Alcohol. The relationship between alcohol intake and fracture risk is dose-dependent. Where alcohol intake is on average two units or less daily there is no increase in risk. Indeed, some studies suggest that BMD and fracture risk may be reduced. Intakes of 3 or more units daily are associated with a dose-dependent increase in risk [133].

7. Rheumatoid arthritis. There are many secondary causes of osteoporosis associated with an increase in fracture risk (e.g. inflammatory bowel disease, endocrine disorders), but in most instances it is uncertain to what extent the high fracture risk is dependent on low BMD or other risk factors (e.g. the use of glucocorticoids). By contrast, rheumatoid arthritis causes a fracture risk independently of BMD and the use of glucocorticoids [132].

\section{Biochemical assessment of fracture risk}

Bone markers are increased after the menopause, and in several studies the rate of bone loss varies according to the marker value [110]. Thus, a potential clinical application of biochemical indices of skeletal metabolism is in assessing fracture risk. Several prospective studies have shown that the serum levels and urinary excretion of markers of bone turnover correlate with subsequent risk of fractures in postmenopausal women $[110,134]$. Thus, women who have marker values of bone turnover above the premenopausal range (25-40\% of postmenopausal women) have been shown in several-but not all-studies to have approximately a two-fold increased risk of vertebral and non-vertebral fractures, including those at the hip, independently of age and of BMD.

\section{Case-finding}

At present there is no universally accepted policy for population screening in Europe to identify patients with osteoporosis or those at high risk of fracture. With the increasing development of effective agents and price reductions, this view may change, particularly in the case of elderly people. In the absence of such policies, patients are identified opportunistically using a case-finding strategy on the finding of a previous fragility fracture or the

Table 10 Clinical risk factors used for the assessment of fracture probability

Risk factor

Age

Sex

Low body mass index

Previous fragility fracture, particularly of the hip, wrist and spine including morphometric vertebral fracture

Parental history of hip fracture

Glucocorticoid treatment ( $>5 \mathrm{mg}$ prednisolone daily or equivalent for 3 months or more)

Current smoking

Alcohol intake 3 or more units daily

Secondary causes of osteoporosis

Rheumatoid arthritis

Untreated hypogonadism in men and women, e.g. premature menopause, bilateral oophorectomy or orchidectomy, anorexia nervosa, chemotherapy for breast cancer, hypopituitarism

Inflammatory bowel disease, e.g. Crohn's disease and ulcerative colitis. It should be noted that the risk is in part dependent on the use of glucocorticoids, but an independent risk remains after adjustment for glucocorticoid exposure

Prolonged immobility, e.g. spinal cord injury, Parkinson's disease, stroke, muscular dystrophy, ankylosing spondylitis

Organ transplantation

Type I diabetes

Thyroid disorders, e.g. untreated hyperthyroidism, over-treated hypothyroidism

Chronic obstructive pulmonary disease 
presence of significant risk factors. The risk factors that are used for clinical assessment are summarised in Table 10 [19]. Markers of bone turnover are not included since they have not been validated in enough cohorts worldwide to be readily incorporated into the algorithms.

To date, treatment of osteoporosis has largely been directed at women with clinical risk factors determined by a set BMD. The finding that the presence of clinical risk factors and age modulate risk (and therefore cost-effectiveness), reinforces the view that treatment should be directed on the basis of fracture probability, rather than on a single BMD threshold [18, 19, $118,125,135,136]$. The preferred metric is the probability of fracture, but practising physicians are not yet familiar with the assessment of fracture probability, although algorithms will shortly be available to assess these $[18,19]$.

A possible algorithm for case-finding is shown in Fig. 3 [137]. It is based on knowledge of the interactions of the clinical risk factors, age and BMD and is applied to the UK. Its rationale is reviewed later (see Health economics). The management algorithm provides for the treatment of patients with a previous fragility fracture without the need for a BMD test, since a prior fracture is a very strong risk factor that is largely independent of BMD. For the other risk factors treatment can be delivered cost-effectively in women aged 65 years or more, but in women below this age, further stratification of risk is indicated with a BMD test. For women with a parental history of hip fracture, treatment becomes worthwhile with a BMD T-score of -1 SD or less at the femoral neck or total hip. For women taking long-term glucocorticoids, a T-score threshold of $-2.0 \mathrm{SD}$ is appropriate, whereas for the weaker risk factors (secondary causes of osteoporosis, current smoking and alcohol consumption of 3 or more units daily), an appropriate threshold would be a T-score of $-2.5 \mathrm{SD}$. The schema illustrates the advantage to patients in not using a single T-score value to judge suitability for treatment as has been widely practised in Europe. Although treatment can be given cost-effectively in many patients without the need for a BMD test, it is a commonly held view that treatment should not be undertaken in women without recourse to a BMD test except in women with prior fragility fractures. The adoption of such a strategy would not adversely affect estimates of cost-effectiveness, since BMD testing was included in all scenarios. Rather, the avoidance of BMD testing would make treatment even more cost-effective.

Whereas this schema can be justified from a health economic perspective in the UK, other factors will determine whether similar thresholds for age and BMD are appropriate for individual countries.

\section{Comparison of case-finding strategies}

The utility of a bone densitometry service has been previously evaluated for the UK following the guidelines of the European Foundation for Osteoporosis (now the International Osteoporosis Foundation). The use of bone densitometry was considered to be justifiable in terms of the cost per averted fracture and more cost-effective than the treatment of patients with risk factors in whom BMD was not known [30].

The effectiveness of the case-finding strategy previously used in Europe (EUR) [30] has been compared with that

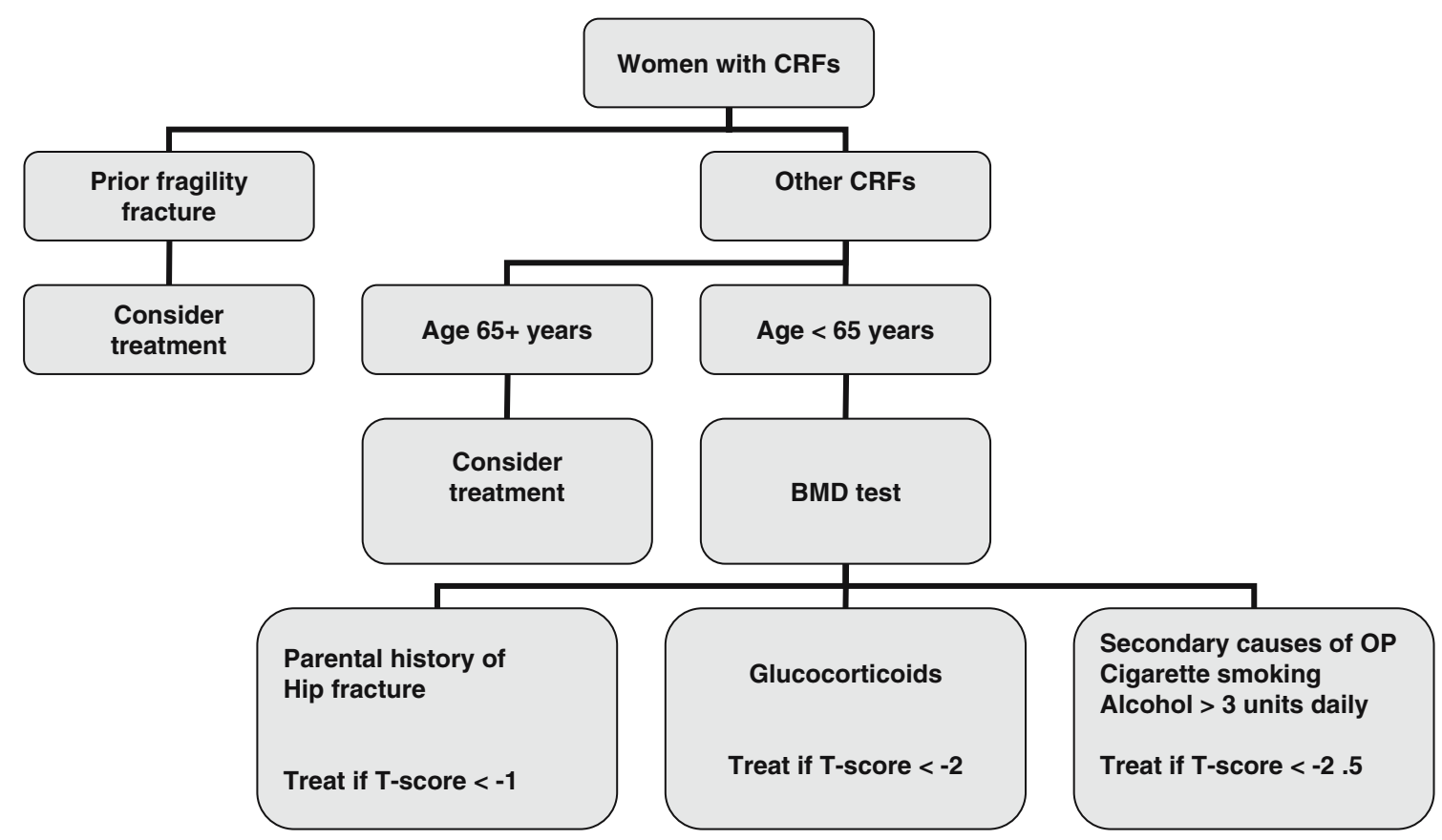

Fig. 3 Management algorithm in postmenopausal women based on an health economic analysis for the UK. (Adapted from [137]) 
Table 11 Comparison of previous guidelines with present guidelines (Reprinted from [138], with kind permission from Springer Science + Business Media)

\begin{tabular}{|c|c|c|c|c|c|c|c|}
\hline \multirow[t]{2}{*}{ Age (years) } & \multirow[t]{2}{*}{$\begin{array}{l}\text { Number of DXA } \\
\text { tests } / 1000\end{array}$} & \multicolumn{2}{|c|}{$\begin{array}{l}\text { Number of high } \\
\text { risk women } \\
\text { identified/1000* }\end{array}$} & \multicolumn{2}{|c|}{$\begin{array}{l}\text { Number of hip } \\
\text { fractures } \\
\text { expected* }\end{array}$} & \multicolumn{2}{|c|}{$\begin{array}{l}\text { Number of hip fractures } \\
\text { avoided (cost/avoided } \\
\text { fracture } £ 000)\end{array}$} \\
\hline & & EUR & WHO & EUR & WHO & EUR & WHO \\
\hline 50 & 450 & 26 & 41 & $<1$ & 1 & 0.1 & $0.4(63)$ \\
\hline 60 & 450 & 52 & 65 & 2 & 4 & $0.7(37)$ & $1.2(22)$ \\
\hline 70 & 500 & 120 & 355 & 16 & 30 & $5.7(5)$ & $10.6(3)$ \\
\hline 80 & 550 & 235 & 606 & 51 & 92 & $17.9(1.8)$ & $32.0(1.2)$ \\
\hline
\end{tabular}

$*_{\text {in women at high risk }}$

proposed in the present guideline (WHO) [138]. The comparisons were derived from simulations based on the data of ten prospective population-based cohorts with a follow-up of approximately 250,000 person-years. For this comparison, modelled on the UK, the same risk factors and the same number of BMD tests were used in each approach.

The EUR strategy selected candidates for BMD tests on the basis of the presence of clinical risk factors and treatment recommended where the T-score for BMD was $\leq-2.5 \mathrm{SD}$. For the purpose of this study, the risk factors used comprised a prior history of a fragility fracture, a BMI $<19 \mathrm{~kg} / \mathrm{m}^{2}$, a parental history of hip fracture, long-term use of oral glucocorticoids, rheumatoid arthritis, current smoking and an average intake of alcohol of 3 or more units daily as given in the present guidelines. The number of BMD tests modelled for both strategies was determined, therefore, by the age-specific prevalence of the clinical risk factors. Assuming a treatment efficacy of $35 \%$, the numbers of hip fractures avoided by the two strategies are shown in Table 11 [138].

Compared with the EUR strategy, the WHO approach identifies more patients at high risk of hip fracture and thus makes more effective use of BMD tests. At each age, the cost per averted hip fracture is lower with the WHO approach.

\section{Integrating risk factors}

The use of clinical risk factors in conjunction with BMD and age improves sensitivity of fracture prediction without adverse effects on specificity. The multiplicity of these risk factors poses problems in the units of risk to be used. The $\mathrm{T}$-score becomes of little value in that different $\mathrm{T}$-score thresholds for treatment would be required for each combination of risk factors. Although the use of relative risks is feasible, the metric of risk best suited for clinicians is the absolute risk (or probability) of fracture.

Fracture probability

The absolute risk of fracture depends upon age and life expectancy as well as the current relative risk. In general, the remaining lifetime risk of fracture decreases with age, especially after the age of 70 years or so since the risk of death with age outstrips the increasing incidence of fracture with age. Estimates of lifetime risk are of value in considering the burden of osteoporosis in the community, and the societal effects of intervention strategies. For several reasons they are less relevant for assessing risk in individuals in whom treatment might be envisaged [119]; therefore, the IOF and the WHO recommend that risk of fracture should be expressed as a short-term absolute risk, i.e. probability over a 10-year interval [118]. The period of 10 years covers the likely duration of treatment and the benefits that may continue once treatment is stopped.

The major advantage of using absolute fracture probability is that it standardises the output from the multiple techniques and sites used for assessment and incorporates the additional information derived from age and the clinical risk factors. The estimated probability will of course depend upon the performance characteristics (gradient of risk) provided by any technique at any one site.

The general relationship between relative risk and 10-year probability of hip fracture is shown in Table 12 [119]. For example, a woman at the age of 60 years has on average a 10 -year probability of hip fracture of $2.4 \%$. In the presence of a prior fragility fracture this risk is increased approximately 2 -fold and the probability increases to $4.8 \%$. The integration of risk factors is not new and has been successfully applied in the management of coronary heart disease [139].

Table 12 Ten-year probability of fracture in women from Sweden according to age and the relative risk (RR) to the average population (Reprinted from [119], with permission from Elsevier)

\begin{tabular}{lllll}
\hline \multicolumn{5}{c}{ Age (years) } \\
\cline { 2 - 5 } RR & 50 & 60 & 70 & 80 \\
\hline (a) Hip fracture & & & \\
1 & 0.57 & 2.40 & 7.87 & 18.00 \\
2 & 1.14 & 4.75 & 15.1 & 32.0 \\
3 & 1.71 & 7.04 & 21.7 & 42.9 \\
4 & 2.27 & 9.27 & 27.7 & 51.6 \\
(b) Hip, clinical spine, humeral or Colles' fracture & \\
1 & 5.8 & 9.6 & 16.1 & 21.5 \\
2 & 11.3 & 18.2 & 29.4 & 37.4 \\
3 & 16.5 & 26.0 & 40.0 & 49.2 \\
4 & 21.4 & 33.1 & 49.5 & 58.1 \\
\hline
\end{tabular}


Table 13 Classification of European countries according to the population risk of hip fracture (Adapted from [141])

\begin{tabular}{lll}
\hline Category of risk & Index country & Similar countries \\
\hline Very high & Sweden & Denmark \\
& & Iceland \\
& & Norway \\
High & UK & Germany \\
& Italy & Finland \\
& & Germany \\
& & Greece \\
& & Hungary \\
& & Netherlands \\
& & Portugal \\
Medium & Switzerland \\
Low & France & \\
\hline
\end{tabular}

Case finding with fracture probabilities

Algorithms that integrate the weight of clinical risk factors for fracture risk with or without information on BMD have been developed by the WHO Collaborating Centre for Metabolic Bone Diseases at Sheffield, UK. The FRAX ${ }^{\mathrm{TM}}$ tool http://www.shef.ac.uk/FRAX) computes the 10-year probability of hip fracture or a major osteoporotic fracture. A major osteoporotic fracture is a clinical spine, hip, forearm or humerus fracture. Probabilities can be computed for the index of European countries shown in Table 13, categorised for different levels of risk [140]. Where a country is not represented (because of the lack of epidemiological data) a surrogate should be chosen.

Where computer access is limited, paper charts can be downloaded that give fracture probabilities for each index country http://www.shef.ac.uk/FRAX) according to the number of clinical risk factors. An example is given in Table 14 for women aged 60 years in the UK. Thus, a woman from the UK aged 60 years with a body mass index (BMI) of $20 \mathrm{~kg} / \mathrm{m}^{2}$ with a prior forearm fracture and ulcerative colitis (i.e. two clinical risk factors) has a 10-year fracture probability of $15 \%(9-24 \%)$. The range is not a confidence interval, but, because the weight of different risk factors varies, it is a true range.

Measurement of BMD is indicated in individuals who have a high fracture probability, provided that it will influence the management decision. This is preferred to blind treatment, because not all patients with clinical risk factors will have low BMD. In some instances, treatment will be justified without measurement of BMD, for example in patients with fragility fractures and other strong risk factors. In other instances, the low cost and absence of side effects justify the use of some agents without BMD measurements in populations (e.g. calcium with vitamin $\mathrm{D}$ in the institutionalised elderly). In other patients, the fracture probability may be so low that a management decision will not be changed by information on BMD. An example is a woman at the time of natural menopause without symptoms and with none of the clinical risk factors. This does not preclude the measurement of BMD in people without risk factors in patients who would take treatment if their BMD were low. The general approach is shown in Fig. 4 [19]. The size of the intermediate group in Fig. 4 in whom a BMD test would be recommended will vary by region and country. In countries with very limited or no access to central DXA, the size of this segment will be very small. In those countries where screening is recommended (e.g. in women at the age of 65 years or older) this segment will include the majority of women.

The measurement of BMD provides the opportunity to reassess fracture probability in the light of the test result and the clinical risk factors. Probabilities can be computed for the index European countries shown in Table 13 [19]. Where computer access is limited, FRAX ${ }^{\mathrm{TM}}$ charts can be downloaded that give fracture probabilities for each index country according to femoral neck BMD and the number of clinical risk factors. An example is given in Table 15 for women in the UK at the age of 60 years. Such a woman

Table 14 FRAX $^{\mathrm{TM}}$ table for the 10-year probability (\%) of a major osteoporotic fracture (clinical spine, hip, forearm or humerus fracture) according to body mass index (BMI), the number of clinical risk

factors (CRFs) for women aged 60 years in the UK. The range is not a confidence interval but, because the weight of different risk factors varies, it is a true range. (Reprinted from [19], with permission)

\begin{tabular}{|c|c|c|c|c|c|c|c|}
\hline \multirow[t]{2}{*}{ Number of CRFs } & \multicolumn{7}{|l|}{ BMI $\left(\mathrm{kg} / \mathrm{m}^{2}\right)$} \\
\hline & 15 & 20 & 25 & 30 & 35 & 40 & 45 \\
\hline 0 & 7.4 & 6.5 & 6.0 & 5.2 & 4.6 & 4.0 & 3.5 \\
\hline 1 & $12(8.4-16)$ & $10(7.2-13)$ & $9.3(6.5-12)$ & $8.1(5.6-11)$ & $7.0(4.9-9.2)$ & $6.1(4.2-8.0)$ & $5.3(3.7-7.0)$ \\
\hline 2 & $18(11-26)$ & $15(9.0-24)$ & $14(7.9-22)$ & $12(6.9-20)$ & $11(5.9-17)$ & $9.2(5.1-15)$ & $8.1(4.4-13)$ \\
\hline 3 & $27(16-40)$ & $23(13-36)$ & $20(11-34)$ & $18(9.5-30)$ & $16(8.2-27)$ & $14(7.1-24)$ & $12(6.1-21)$ \\
\hline 4 & $39(26-53)$ & $33(22-47)$ & $29(18-44)$ & $26(16-39)$ & $23(14-35)$ & $20(12-31)$ & $17(10-27)$ \\
\hline
\end{tabular}

(C) World Health Organization Collaborating Centre for Metabolic Bone Diseases, University of Sheffield, UK 


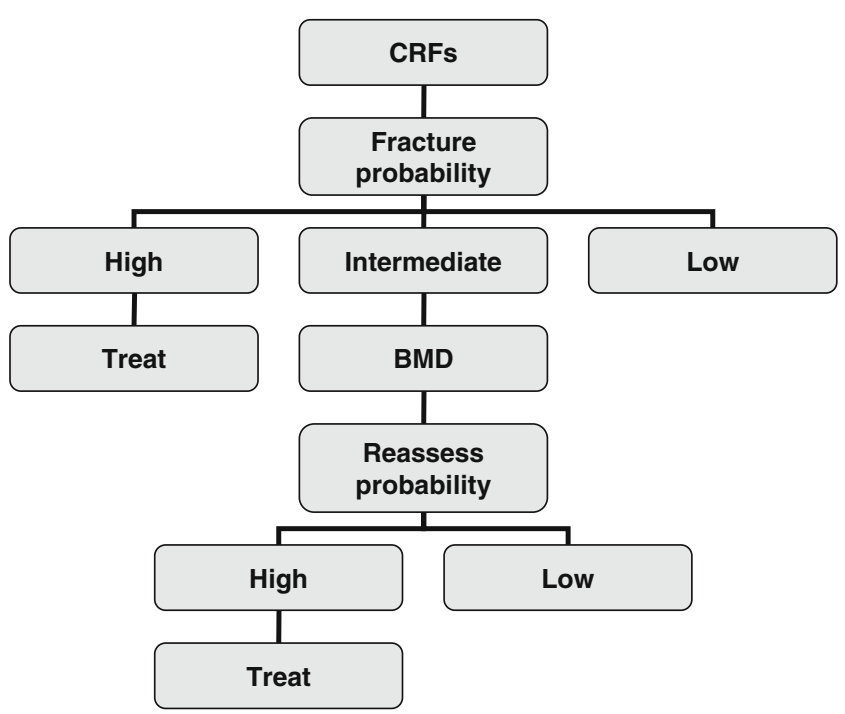

Fig. 4 Algorithm for the assessment of fracture probability. (Reprinted from [20], with permission)

with a T-score for femoral neck BMD of $-3.0 \mathrm{SD}$ with rheumatoid arthritis and taking oral glucocorticoids (i.e. two clinical risk factors) has a 10 -year fracture probability of $25 \%(19-34 \%)$. As before, the range is not a confidence interval, but, because the weight of different risk factors varies, it is a true range. Note that a secondary cause of osteoporosis, with the exception of rheumatoid arthritis, does not add weight to the fracture risk assessment where BMD is known. Thus, a woman from the UK aged 60 years with a T-score for femoral neck BMD of $-3.0 \mathrm{SD}$ a prior forearm fracture and ulcerative colitis (i.e. one relevant clinical risk factor) has a 10 -year fracture probability of $18 \%$ (15-21\%). The relationship between fracture probability and intervention thresholds is reviewed later (see Health economics).

\section{Limitations}

The assessment takes no account of dose-responses for several risk factors. For example, two prior fractures carry a much higher risk than a single prior fracture. Dose-

Table 15 FRAX $^{\mathrm{TM}}$ table for the 10-year probability (\%) of a major osteoporotic fracture (clinical spine, hip, forearm or humerus fracture) according to $\mathrm{BMD}$, the number of clinical risk factors (CRFs) for responses are also evident for glucocorticoid use. An example is given in Fig. 5 [131]. A prior clinical vertebral fracture carries an approximately two-fold higher risk than other prior fractures. Since it is not possible to model all such scenarios with the FRAX ${ }^{\mathrm{TM}}$ algorithm, these limitations should temper clinical judgement.

A further limitation is that the FRAX ${ }^{\mathrm{TM}}$ algorithm uses T-scores for femoral neck BMD. Whereas the performance characteristics of BMD at this site are as good as or better than other sites, the question arises whether T-scores from other sites and technologies can be used. Unfortunately, the $\mathrm{T}$-score and Z-score vary according to the technology used and the site measured. In the case of total hip BMD, however, this can be used interchangeably with femoral neck BMD in women, but not in men. Where the performance characteristics are known (i.e. gradient of risk or risk ratios) probabilities can be determined from tables in development.

\section{Investigation of patients with osteoporosis}

\section{Diagnostic work-up}

The same diagnostic approach should be undertaken in all patients with osteoporosis irrespective of the presence or absence of fragility fractures. However, the range of clinical and biological tests will depend on the severity of the disease, the age at presentation and the presence or absence of vertebral fractures. The aims of the clinical history, physical examination and clinical tests are:

1. To exclude a disease that can mimic osteoporosis (e.g. osteomalacia, myelomatosis)

2. To elucidate the causes of osteoporosis and contributory factors

3. To assess the severity of osteoporosis to determine the prognosis of the disease, i.e. the risk of subsequent fractures

4. To select the most appropriate form of treatment

women aged 60 years in the UK. THE range is not a confidence interval, but, because the weight of different risk factors varies, it is a true range. (Reprinted from [19] with permission)

\begin{tabular}{|c|c|c|c|c|c|c|}
\hline \multirow[t]{2}{*}{ Number of CRFs } & \multicolumn{6}{|c|}{ BMD T-score (femoral neck) } \\
\hline & -4.0 & -3.0 & -2.0 & -1.0 & 0 & 1.0 \\
\hline 0 & 23 & 12 & 7.7 & 5.5 & 4.6 & 4.1 \\
\hline 1 & $32(29-37)$ & $18(15-21)$ & $11(8.2-14)$ & $8.0(5.5-11)$ & $6.8(4.5-9.5)$ & $6.0(3.9-8.4)$ \\
\hline 2 & $44(38-54)$ & $25(19-34)$ & $16(10-24)$ & $12(6.7-18)$ & $9.8(5.4-16)$ & $8.6(4.6-14)$ \\
\hline 3 & $58(48-68)$ & $35(25-49)$ & $23(14-36)$ & $16(8.7-28)$ & $14(6.9-25)$ & $12(5.9-22)$ \\
\hline 4 & $71(59-78)$ & $46(35-59)$ & $31(22-44)$ & $22(14-35)$ & $19(11-31)$ & $17(9.4-28)$ \\
\hline
\end{tabular}

(C) World Health Organization Collaborating Centre for Metabolic Bone Diseases, University of Sheffield, UK 
Fig. 5 The effects of glucocorticoid dose on the incidence of fracture. (Reprinted from [131], with kind permission from Springer Science + Business Media)

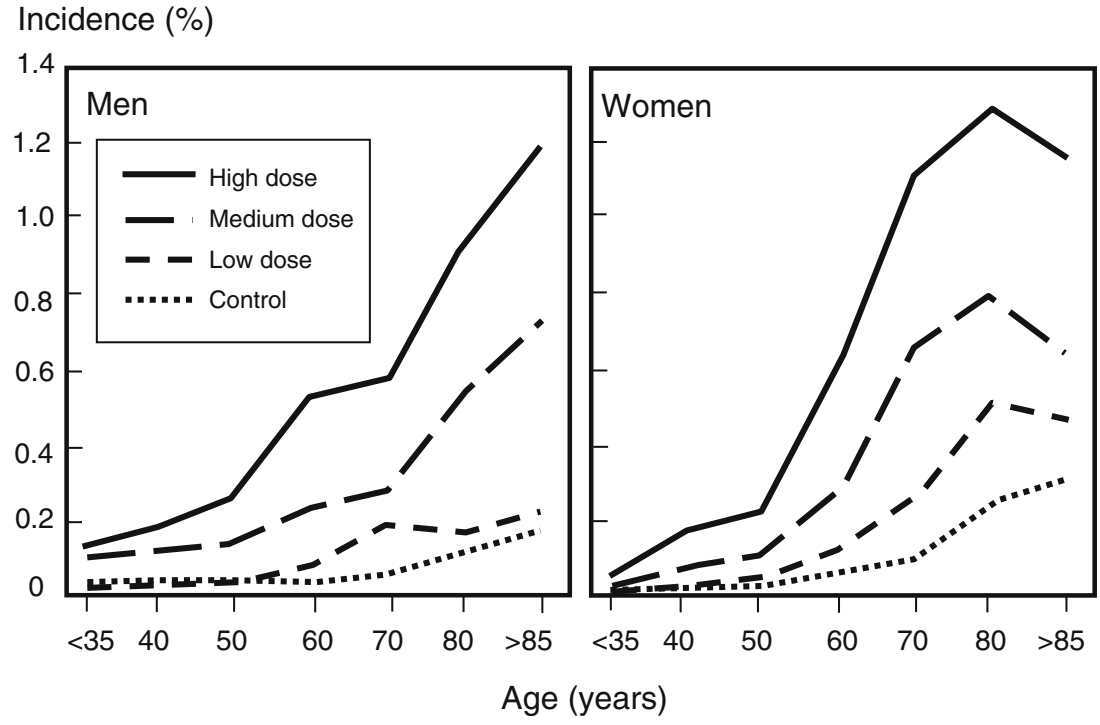

5. To perform baseline measurements for the subsequent monitoring of treatment

The procedures that may be relevant to the investigation of osteoporosis are shown in Table 16. These investigations may be used to:

1. Establish the diagnosis of osteoporosis (e.g. DXA or X-rays

2. Establish the cause (e.g. thyroid function tests for hyperthyroidism, and urinary free cortisol for Cushing syndrome)

3. Establish differential diagnosis (e.g. protein electrophoresis for myeloma, and serum calcium and alkaline phosphatase for osteomalacia)

Investigations commonly reserved for specialist centres include measurement of the biochemical indices of bone turnover, serum parathyroid hormone, serum 25-hydroxyvitamin $\mathrm{D}$, serum or urine protein electrophoresis, fasting and 24-h urinary calcium, urinary free cortisol, thyroid function tests and transiliac bone biopsy. Free testosterone, gonadotrophin and prolactin measurements may be of value in men. Assessment is guided by the clinical findings, and some patients who apparently have primary osteoporosis, are subsequently found to have mild hyperparathyroidism or hyperthyroidism, systemic mastocytosis, the late appearance of osteogenesis imperfecta or osteomalacia.

\section{Differential diagnosis of osteoporosis}

Specific underlying causes of bone loss are more commonly found in men than in women. In a high proportion of men presenting with symptomatic vertebral crush fractures an underlying cause of osteoporosis is identified, such as hypogonadism, oral steroid therapy or alcoholism. Casecontrol studies have shown a significantly increased risk of vertebral fractures with smoking, alcohol consumption and alcoholism, oral glucocorticoid therapy, anticonvulsant treatment, hypogonadism and underlying causes of osteoporosis. For hip fractures, the risk factors in men are similar to those found in women.

Osteomalacia and malignancy commonly induce bone loss and fractures. Osteomalacia is characterised by a defect of mineralisation of bone matrix most commonly attributable to impaired intake, production or metabolism of vitamin D. Other causes include impaired phosphate transport or the chronic use of some drugs such as aluminium salts (and other phosphate-binding antacids), high doses of fluoride or etidronate, and the chronic use of anticonvulsants. In most cases, the diagnosis of osteomalacia is suspected by the clinical history and by abnormalities in biochemical tests such as low values of serum and urinary calcium, serum phosphate and 25-hydroxyvitamin D, and high values for alkaline phosphatase and parathyroid hormone. A transiliac bone biopsy after tetracycline labelling may be necessary to demonstrate unequivocally a defect in mineralisation.

Diffuse osteoporosis with or without pathological fracture is common in patients with multiple myeloma, a condition suspected by the severity of bone pain, increased sedimen-

Table 16 Routine procedures proposed in the investigation of osteoporosis

Procedure

Routine

History and physical examination

Blood cell count, sedimentation rate, serum calcium, albumin,

creatinine, phosphate, alkaline phosphatase and liver transaminases

Lateral radiograph of lumbar and thoracic spine

Bone densitometry (dual energy X-ray absorptiometry)

Other

X-ray-vertebral fracture assessment

Markers of bone turnover, when available 
tation rate and Bence-Jones proteinuria, and identified by marrow aspirate and serum and urine (immuno) electrophoresis of proteins. Similarly, pathological fractures resulting from metastatic malignancies can mimic osteoporosis and can be excluded by clinical and radiological examination, biological tests such as tumour markers, and scintigraphy or other imaging techniques. Vertebral fractures in osteoporosis should be differentiated from vertebral deformities attributable to other disorders such as scoliosis, osteoarthrosis and Scheuermann's disease.

\section{Health economics}

There is an increasing need for management strategies to be placed in an appropriate health economic perspective for guideline development and for reimbursement.

\section{Types of evaluation}

A widely used measure is the "number needed to treat" (NNT) to prevent a fracture. For example, if a treatment reduces the incidence of vertebral fracture from $10 \%$ to $5 \%$ during the conduct of a trial, then 5 fractures are saved for each 100 patients treated, which gives an NNT of 20. There are several limitations in the use of NNT. First, it does not take into account the cost of intervention. Second, its use is only relevant to one population setting. In the example above, the effectiveness of the intervention is $50 \%$. If the same efficacy is found in other populations but at a different absolute risk, the NNT changes. Thus, if the background fracture risk is, say, $5 \%$ and treatment reduces this by half, then the NNT $=40$. A further feature of the use of NNT is that it does not take into account the offset of effect of therapeutic intervention.

In the context of treatments, the most straightforward pharmaco-economic evaluation is cost-minimisation analysis. This approach can be used when two strategies or interventions have identical effects, for example where both agents decrease fracture rates by a fixed percentage, and neither has adverse effects. The advantage of one over the other will then relate only to differences in cost. In practice, the benefits and risks of different strategies are rarely equal. Cost-effectiveness analyses take this into account. In this approach, outcomes are converted into a common currency. Examples include the cost per life-year saved, and the cost per fracture averted. A limitation of using these outcomes is that comparisons across diseases are difficult. Difficulties also arise within the same disease area. The cost per fracture averted has, for example, a different significance where the outcome is a hip fracture rather than a forearm fracture.

These considerations have led to the increasing use of costutility analysis as a measure of cost-effectiveness. In the context of evaluating treatments, this takes into account not only fractures avoided, but also any change in morbidity and mortality from both beneficial and unwanted effects. Qualityadjusted life-years (QALYs) are the accepted unit of measurement in health economic assessment of interventions using cost-utility analysis. In order to estimate QALYs, each year of life is valued according to its utility to the patient. Values range from 0 , the least desirable health state, to 1 , or perfect health. The decrement in utility associated with fractures is the cumulative loss of utility over time. A comparable approach favoured by WHO is the use of disability-adjusted life-years (DALYs). This has been extensively used to characterise the burden of disease worldwide [141].

\section{Willingness to pay}

There is at present little information as to when treatment can be considered to be cost-effective in the majority of countries. One method of estimating the societal value of a QALY is based on the value of a statistical life. Using this approach, the value of a QALY has been estimated at about SEK 655,000 (about $€ 71,000$ - all currency conversions as of October 2007) in Sweden [142]. Another way of inferring threshold values is based on past reimbursement decisions and guidelines made by national government agencies, such as in the UK (€23,000-34,000/QALY), Australia (€20,000-36,000/life year gained) and New Zealand (€7,700/QALY) [143]. Other threshold values that can be derived from the literature vary substantially (from $€ 13,000$ to $€ 460,000$ ), depending on the country, perspective, outcome measure (e.g. life-year or a QALY) and methodology [144]. Yet another approach is to base the threshold value on a measure of a country's economic performance. For example, the WHO Commission on Macroeconomics and Health has suggested that interventions with a cost-effectiveness ratio lower than 3 times the gross domestic product (GDP) per capita for each averted disability-adjusted life-year (DALY) could be considered good value for money in developing countries [145]. Assuming that the value for a DALY and a QALY are reasonably comparable, then a cost-effective threshold for the UK would be $€ 54,000$. It is not specified in the report of the WHO Commission what costs should be included, but if all costs are included (all direct and indirect costs regardless of payer), then the threshold value should be set at a lower level when a health-care perspective (only costs related to the health-care sector considered) is taken. Using the 0.6 ratio for adjustment as suggested by Kanis and Jönsson [144], the threshold values would be about $€ 32,000$ in the UK, close to the recommendation of the National Institute for Health and Clinical Excellence (NICE), and about $€ 9,000$ in Turkey. Although the GDP per capita provides an index of affordability, there is also a 
marked heterogeneity in the proportion of GDP that countries are willing to devote to health care, and in the proportion of the population at risk of osteoporotic fracture (i.e. elderly people). These factors will also affect what is an acceptable price to pay, which needs to be defined on a country by country basis [19].

\section{Studies of intervention}

There has been a rapid expansion of research on the costutility of interventions in osteoporosis, which has recently been reviewed [146, 147]. Attention was originally focussed on hormone replacement treatment, but is now more commonly directed at bone-specific agents. Despite the use of different models, different settings and payer perspectives, analyses suggest that there are cost-effective scenarios that can be found in the context of the management of osteoporosis for all but the most expensive interventions illustrated below in a UK setting.

The cost-effectiveness of the base case treatment (£350) and efficacy (35\% effectiveness) is shown in Fig. 6 for different ages and clinical scenarios [148]. As expected, costeffectiveness improved at any age with increasing fracture probability, because of the higher risk of fracture and thus the greater number of fractures avoided.

In women with a prior fragility fracture, and without knowledge of BMD, it was cost-effective to intervene from the age of 65 years. In women at the threshold of osteoporosis (i.e. a T-score at the femoral neck equal to $-2.5 \mathrm{SD}$ and no prior fracture), it was cost-effective to intervene from the age of 60 years. In women at the threshold of osteoporosis with a T-score of $-2.5 \mathrm{SD}$, it was cost-effective to intervene if there was a history of a prior fracture, irrespective of age. In women with a T-score of less than $-2.5 \mathrm{SD}$ it was, therefore, also cost-

\section{Cost/QALY gained $(£ 000)$}

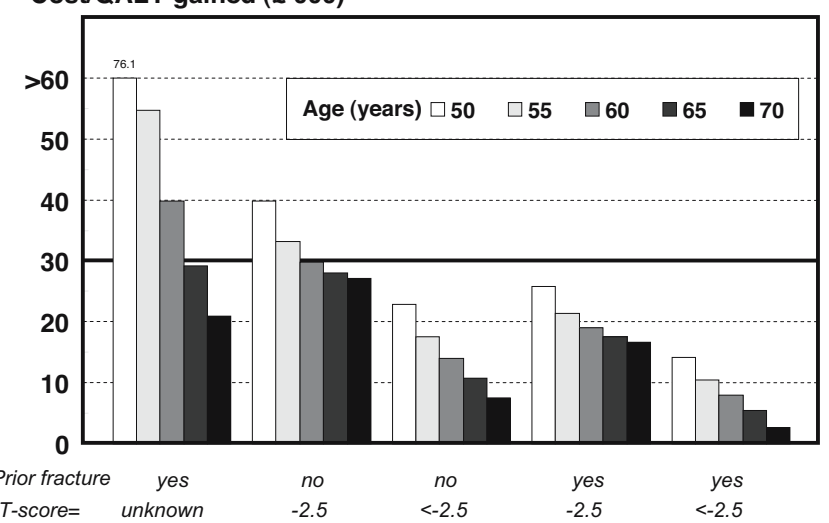

Fig. 6 Cost-effectiveness ( $£ 000 / \mathrm{QALY}$ gained) of treatment in women aged 50-70 years, by the presence or absence of a prior fracture and osteoporosis. (Reprinted from [148], with permission from Elsevier). The solid horizontal line indicates the threshold for cost-effectiveness ( $\{30,000$ - approximately 43,000 Euros - currency conversion here and elsewhere at October 2007) effective to intervene, irrespective of the presence or absence of a prior fragility fracture and irrespective of age. These observations illustrate the important effect of combining independent risk indicators.

\section{A reference model}

A reference health economic model is available for the evaluation of intervention in osteoporosis [149]. The model, constructed in a Swedish setting, can be used for analysing different populations: female or male, high-risk populations, and different ages. The model produces the change in costs and effectiveness (in terms of QALYs) for intervention compared with no intervention. The model uses a societal perspective where direct and indirect costs related to intervention, morbidity and mortality are included. As an option, mortality costs (costs in added life-years) may be excluded. The model also provides an opportunity to incorporate negative (side effects) or positive effects during therapy. An interface version and a description of the model are available on the internet http://www.iofbonehealth.org/ health-professionals/health-economics/cost-effectivenessmodel.html). The model permits the estimation of the costeffectiveness over different ranges for a selected number of parameters (e.g. age, fracture risk, cost of intervention).

There are several reasons why a reference model is needed. First, it may be used as a common reference for the assessment of new therapies. If every new technology is accompanied by a new model it may be difficult to conclude whether the costeffectiveness results are a consequence of the model or of the new technology. Second, new models can be validated against the reference model based on a given set of data. Such a validation provides an opportunity to discuss and compare results and clarify the reasons for discrepancies. Third, it will provide an opportunity to use a well-validated model to investigate the effect of new data for a specific population (country) or for a new technology.

Intervention thresholds

Intervention thresholds can be defined as the fracture probability at which an intervention becomes acceptable. Decisions about the need for treatment depend not only upon the fracture probability, but also the efficacy, costs and side effects of treatment and the willingness to pay. All these differ between countries, so that intervention threshold will differ accordingly. In Europe, intervention thresholds have been estimated for Austria, Germany, Spain, Sweden and the UK [148, 150-153] using a cost-effectiveness analysis to determine the hip fracture probability at which intervention with a bisphosphonate becomes cost-effective.

Developments in the ability to assess fracture probability in individuals rather than in populations pose new chal- 
lenges for the health economic evaluation of interventions. In addition, the cost of intervention has decreased with the introduction of generic alendronate in some European countries. These developments mean that previous estimates of intervention thresholds based on cost-effectiveness need to be revised using models that integrate the weights of the different clinical risk factors on the risk of fracture and death $[137,154]$.

\section{Setting intervention thresholds}

For the purposes of this guidance, the cost-effectiveness of a 5 -year treatment with alendronate is compared with no intervention in a UK setting by simulating costs and outcomes in cohorts of women from the age of 50 years with different combinations of clinical risk factors for fracture [137]. The UK was chosen because the fracture risk lies intermediate between the very high risks of the Nordic countries and the lower risks of Southern Europe. Alendronate was chosen because of the lower price of generic formulations currently available in Europe. Since the price of alendronate is very low in the UK and is unlikely to be sustained in Europe, the price of alendronate was set at 1 Euro daily. The analysis took a health-care perspective that included only direct costs. The results are shown as the incremental cost-effectiveness ratio (ICER), i.e. cost/QALY gained. A threshold value of $£ 30,000 /$ QALY gained was taken as being cost-effective (approximately 43,000 Euros).

Other interventions were examined in a sensitivity analysis in women aged 70 years at the BMD threshold for osteoporosis, at the BMD threshold for osteoporosis with a prior fragility fracture, and in women with a prior fragility fracture but no BMD test. The relative risks of fracture with treatments were taken from a meta-analysis [52]. In the case of raloxifene, an effect of the agent on breast cancer was also incorporated $(\mathrm{RR}=0.38 ; 95 \%$ confidence interval $=0.24-0.58$ ) $[155]$. For strontium ranelate, an additional scenario was modelled that included a post hoc analysis, accepted by the Committee of Human Medicinal Products of the European Medicines Evaluation Agency, showing a marked effect on hip fracture risk [74]. Oral ibandronate was also modelled, based on a study using $2.5 \mathrm{mg}$ daily or an intermittent regimen of $20 \mathrm{mg}$ on alternate days for 12 doses every 3 months [58]. Other assumptions are given elsewhere [136].

\section{Thresholds in the UK}

The cost-effectiveness of alendronate directed at women at the threshold of osteoporosis is shown in Table 17. In women with osteoporosis (i.e. a femoral neck T-score equal to $-2.5 \mathrm{SD}$ ) the ICER was stable up to the age of 60 years
Table 17 Cost-effectiveness of intervention with alendronate in women at the threshold of osteoporosis, with or without a prior fracture and in women with a previous fracture without $\mathrm{BMD}^{\mathrm{a}}$

\begin{tabular}{llll}
\hline $\begin{array}{l}\text { Cost }(£ 000) / \text { QALY gained } \\
\begin{array}{l}\text { Age } \\
\text { years) }\end{array}\end{array}$ & $\begin{array}{l}\text { T-score }=-2.5 \\
\text { No previous } \\
\text { fracture }\end{array}$ & $\begin{array}{l}\text { T-score }=-2.5 \\
+ \text { Previous fracture }\end{array}$ & $\begin{array}{l}\text { No BMD } \\
+ \text { Previous fracture }\end{array}$ \\
\hline 50 & 38.9 & 14.3 & $28.6(29.1)$ \\
55 & 31.7 & 16.9 & $27.0(28.4)$ \\
60 & 29.2 & 15.7 & $23.2(24.5)$ \\
65 & 16.1 & 8.1 & $11.5(9.4)$ \\
70 & 10.9 & 4.7 & $6.3($ c.s. $)$ \\
75 & 13.3 & 5.4 & 5.2 (c.s.) \\
80 & 13.4 & 4.4 & c.s. (c.s.) \\
\hline
\end{tabular}

c.s.: cost saving

${ }^{a}$ BMI set to $26 \mathrm{~kg} / \mathrm{m}^{2}$ and in parentheses to $18 \mathrm{~kg} / \mathrm{m}^{2}$

and, thereafter, decreased progressively with increasing age. Treatment was cost-effective from the age of 60 years assuming a willingness to pay of $£ 30,000 / \mathrm{QALY}$. Treatment was also cost-effective at all ages in women who had previously sustained a fragility fracture with a BMD set at the threshold of osteoporosis. A prior fragility fracture was a sufficiently strong risk factor that treatment was costeffective even in women without other risk factors in whom BMD was not known (see Table 17). Indeed, treatment was cost saving at the age of 80 years. With a low BMI, treatment was cost saving from the age of 70 years.

The effect of different clinical risk factors at different T-scores for BMD is shown in Table 18. Prior fractures and a parental history of hip fracture were the strongest risk factors and treatment was cost-effective across all ages with a T-score of $-1.5 \mathrm{SD}$ or less. The use of glucocorticoids had a lesser impact on cost-effectiveness, but across all ages the ICER lay below a $£ 30,000$ threshold in women with a T-score of $-2.0 \mathrm{SD}$ or below. The presence of rheumatoid arthritis had a lesser impact on cost-effectiveness, but across all ages the ICER lay below a $£ 30,000$ threshold of cost-effectiveness with T-scores in the range for osteoporosis. Current smoking and excessive alcohol intake were the weakest of the clinical risk factors and, cost-effectiveness was confined to the lower T-scores and higher ages using a $£ 30,000$ threshold.

In women with a prior fracture, treatment was cost-effective at all ages after the age of 50 years, even in the absence of a BMD test (Table 19). With a parental history of hip fracture, treatment was cost-effective at all ages after the age of 55 years even in the absence of a BMD test. For the other clinical risk factors the ICER lay above the cost-effectiveness threshold at younger ages, but treatment was cost-effective from the age of 65 years with any single risk factor.

These analyses form the basis of the recommendations given for case-finding (see Fig. 3) in that each of the man- 
Table 18 Cost-effectiveness of intervention (cost $£ 000 /$ QALY gained) in women with clinical risk factors according to age and T-score for femoral neck BMD. Calculations are based on the UK (see text for details)

\begin{tabular}{|c|c|c|c|c|c|c|c|c|}
\hline \multirow[t]{2}{*}{ Age (years) } & \multicolumn{8}{|c|}{ T-score (SD) } \\
\hline & 0 & -1 & -2 & -3 & 0 & -1 & -2 & -3 \\
\hline & \multicolumn{4}{|c|}{ Prior fracture } & \multicolumn{4}{|c|}{ Family history } \\
\hline 50 & 35.6 & 30.9 & 21.1 & 8.8 & 31.9 & 28.9 & 21.9 & 13.0 \\
\hline 60 & 35.9 & 30.5 & 20.9 & 8.7 & 30.6 & 27.1 & 20.2 & 12.8 \\
\hline 70 & 18.7 & 14.2 & 8.5 & 1.0 & 19.0 & 13.7 & 6.8 & c.s. \\
\hline \multirow[t]{2}{*}{80} & 44.7 & 27.9 & 12.7 & c.s. & 27.5 & 6.2 & c.s. & c.s. \\
\hline & \multicolumn{4}{|c|}{ Glucocorticoids } & \multicolumn{4}{|c|}{ Rheumatoid arthritis } \\
\hline 50 & 44.1 & 38.8 & 27.0 & 12.2 & 51.5 & 44.4 & 30.5 & 14.3 \\
\hline 60 & 43.5 & 37.5 & 25.9 & 11.1 & 48.9 & 41.5 & 28.3 & 14.8 \\
\hline 70 & 21.8 & 16.7 & 9.4 & c.s. & 23.9 & 18.2 & 10.9 & 1.9 \\
\hline \multirow[t]{2}{*}{80} & 46.4 & 27.8 & 8.6 & c.s. & 51.1 & 30.9 & 13.0 & c.s. \\
\hline & \multicolumn{4}{|c|}{ Alcohol $>3$ units daily } & \multicolumn{4}{|c|}{ Current smoking } \\
\hline 50 & 56.1 & 47.8 & 32.0 & 14.1 & 74.5 & 63.1 & 40.6 & 16.9 \\
\hline 60 & 52.9 & 44.4 & 29.6 & 14.8 & 73.5 & 61.5 & 54.0 & 18.9 \\
\hline 70 & 26.1 & 19.4 & 11.2 & 1.4 & 37.8 & 28.4 & 16.2 & c.s. \\
\hline 80 & 53.0 & 31.3 & 12.3 & c.s. & 75.9 & 44.9 & 16.8 & c.s. \\
\hline
\end{tabular}

agement strategies proposed are cost-effective. The 10-year probability of a major osteoporotic fracture at which intervention becomes cost-effective is approximately $7.5 \%$.

In the presence of more than one clinical risk factor the ICER depends on the weight of the clinical risk factor. In the absence of information on BMD, the combination of any two risk factors gives an ICER of less than $£ 30,000$ from the age of 65 years. Below the age of 65 years, treatment is costeffective with a T-score of $-2.5 \mathrm{SD}$ with the weakest risk factors. With three clinical risk factors, treatment is costeffective at the age of 50 years with a T-score of $-2.0 \mathrm{SD}$ and at the age of 60 years with a T-score of $-1.5 \mathrm{SD}$. T-score thresholds would, however, be less stringent in the presence of the stronger risk factors.

\section{Other treatments}

The analysis above focuses on the cost-effectiveness of alendronate (70 mg weekly), but some other interventions compared with no treatment were examined in sensitivity

Table 19 Cost-effectiveness of alendronate (cost $£ 000 / \mathrm{QALY}$ gained) in women with clinical risk factors and no information on BMD ${ }^{\mathrm{a}}$

\begin{tabular}{lllllll}
\hline $\begin{array}{l}\text { Age } \\
\text { (years) }\end{array}$ & $\begin{array}{l}\text { Prior } \\
\text { fracture }\end{array}$ & $\begin{array}{l}\text { Secondary } \\
\text { OP }\end{array}$ & FH & Smoking & c.s. & Alcohol \\
\hline 50 & 28.6 & 46.4 & 32.1 & 64.6 & 43.8 & 52.1 \\
55 & 27.1 & 42.2 & 29.9 & 60.1 & 41.0 & 47.7 \\
60 & 23.2 & 35.4 & 25.9 & 52.5 & 36.1 & 40.2 \\
65 & 11.5 & 17.5 & 13.4 & 27.7 & 18.5 & 20.2 \\
70 & 6.3 & 9.5 & 7.5 & 16.6 & 10.0 & 11.6 \\
75 & 5.2 & 7.0 & c.s. & 14.8 & 6.3 & 9.8 \\
80 & c.s. & c.s. & c.s. & 4.7 & c.s. & 2.2 \\
\hline
\end{tabular}

Calculations are based on the UK (see text for details)

${ }^{\mathrm{a}} \mathrm{BMI}$ set at $26 \mathrm{~kg} / \mathrm{m}^{2}$ analysis (etidronate, strontium ranelate, raloxifene, ibandronate and risedronate) [137]. As expected, other treatments were less cost-effective than alendronate (Table 20), but the ICER fell below a $£ 30,000 / Q A L Y$ threshold for all treatments with the exception of intermittent ibandronate in women with a BMD T-score of $-2.5 \mathrm{SD}$ and no prior fracture. As might be expected, raloxifene became less costeffective when the effects on breast cancer were ignored.

Despite differences in apparent cost-effectiveness, there is, however, no proven difference in efficacy among the majority of treatments [156,157] and head-to-head comparisons of interventions with fracture outcomes are not available. For these reasons, the value of an incremental analysis between the individual treatments is questionable, since any resulting hierarchy of treatments is dependent largely on price, but otherwise meaningless in clinical terms. In addition, the large

Table 20 Comparison of the cost-effectiveness (cost $£ 000 / \mathrm{Q} A L Y$ gained) of alendronate with other interventions in women aged 70 years. (Data for treatments other than alendronate from [138], with permission from Elsevier)

\begin{tabular}{|c|c|c|c|}
\hline \multirow[t]{2}{*}{ Intervention } & \multicolumn{2}{|c|}{ T-score $=-2.5 \mathrm{SD}$} & \multirow{2}{*}{$\begin{array}{l}\text { No BMD } \\
\text { Prior } \\
\text { fracture }\end{array}$} \\
\hline & $\begin{array}{l}\text { No prior } \\
\text { fracture }\end{array}$ & $\begin{array}{l}\text { Prior } \\
\text { fracture }\end{array}$ & \\
\hline Alendronate & 6,225 & 4,727 & 6,294 \\
\hline Etidronate & 12,869 & 10,098 & 9,093 \\
\hline Ibandronate daily & 20,956 & 14,617 & 14,694 \\
\hline Ibandronate intermittent & 31,154 & 21,587 & 21,745 \\
\hline Raloxifene & 11,184 & 10,379 & 10,808 \\
\hline $\begin{array}{l}\text { Raloxifene without breast } \\
\text { cancer }\end{array}$ & 34,011 & 23,544 & 23,755 \\
\hline Risedronate & 18,271 & 12,659 & 13,853 \\
\hline Strontium ranelate & 25,677 & 18,332 & 19,221 \\
\hline $\begin{array}{l}\text { Strontium ranelate, post } \\
\text { hoc analysis }\end{array}$ & 18,628 & 13,077 & 13,673 \\
\hline
\end{tabular}


Table 21 Categories of risk used for health economic comparisons [166]

\begin{tabular}{|c|c|c|c|c|}
\hline \multirow[t]{2}{*}{ Disease } & \multicolumn{4}{|l|}{ Risk category } \\
\hline & I & II & III & IV \\
\hline Osteoporosis & $\begin{array}{l}\text { BMD T-score }= \\
-2.5 \mathrm{SD}\end{array}$ & $\begin{array}{l}\text { BMD T-score }= \\
-3.0 \mathrm{SD}\end{array}$ & $\begin{array}{l}\text { BMD T-score }=-2.5 \mathrm{SD} \text { and } \\
\text { prior vertebral fracture }\end{array}$ & $\begin{array}{l}\text { BMD T-score }=-3.0 \mathrm{SD} \text { and } \\
\text { prior vertebral fracture }\end{array}$ \\
\hline Hypertension & $\mathrm{SBP}=140$ & $\mathrm{SBP}=160$ & $\mathrm{SBP}=140$ and diabetes & $\mathrm{SBP}=160$ and diabetes + smoking \\
\hline Hyperlipidaemia & TC $7.25 \mathrm{mmol} / \mathrm{l}$ & $\begin{array}{l}\text { TC } 7.25 \mathrm{mmol} / 1, \mathrm{HDL} \\
1.3 \mathrm{mmol} / 1\end{array}$ & $\begin{array}{l}\text { TC } 7.25 \mathrm{mmol} / 1, \mathrm{HDL} \\
1.3 \mathrm{mmol} / \mathrm{l} \text { and diabetes }\end{array}$ & $\begin{array}{l}\text { TC } 7.25 \mathrm{mmol} / 1, \mathrm{HDL} 1.3 \mathrm{mmol} / \mathrm{l}, \\
\text { diabetes and smoking }\end{array}$ \\
\hline
\end{tabular}

SBP: systolic blood pressure (mm Hg); TC: total cholesterol (mmol/l); HDL: high density lipoprotein (mmol/1)

number of untreated patients makes "no treatment" a relevant comparator. Notwithstanding, alendronate can be considered as a first-line intervention. The view arises, not because of apparent differences in efficacy between treatments, but because of cost. The cost-effectiveness of alendronate was greater than that of etidronate, strontium, raloxifene, ibandronate and risedronate in sensitivity analysis. Nevertheless, cost-effective scenarios were found for treatments other than alendronate, providing credible options for patients unable to take alendronate. There are differences, however, in the spectrum of proven efficacy of these alternatives across different fracture sites that will determine their suitability in the clinical management of individuals.

Comparison with the National Institute for Health and Clinical Excellence

The finding of cost-effectiveness for the treatment of osteoporosis is not surprising, given that many treatments in osteoporosis or established osteoporosis, including alendronate, have been shown to be cost-effective in a UK setting [158-160] and that the price of alendronate has decreased in most countries in Europe by about one-third of its former price. These findings, however, contrast markedly with those of the National Institute for Health and Clinical Excellence (NICE) [161, 162], which suggest that the reduction in price, which in the UK had decreased to less than one-third of its former price, had little if any beneficial effect on costeffectiveness. The lack of impact of the price reduction of alendronate on its cost-effectiveness in the technology appraisal of NICE is explained in part by a number of changes in the assumptions contained within the economic model detailed elsewhere [163].

A major difference between the majority of studies and that of NICE is that the latter appraisal used a 10-year rather than a life-time horizon, contrary to its own recommendations [164]. It is unusual to provide 10-year time horizons in chronic diseases. The 10-year horizon captures all the costs of treatment (identification of patients and cost of treatment), but loses a component of the benefit. For example, an individual who dies after 9 years is dead for life, and not for 1 year, as would be assumed in the model. Similar considerations pertain to other consequences of fracture. The penalties for ignoring future costs and effectiveness have been previously shown in the context of osteoporosis [137, 165].

Comparing osteoporosis with other chronic diseases

Information from the literature on the cost-effectiveness of interventions in different diseases is difficult to compare, because of differences in perspectives, data, and model structure. Ideally, a common modelling framework should be adopted to compare the cost-effectiveness of different interventions within and between disease areas.

The cost-effectiveness has been estimated for a female population aged 50-80 years with osteoporosis, hyperlipidaemia and hypertension alone or in combination with risk factors such as diabetes and smoking using the same model construct set in Sweden [166]. Patient groups were defined by age and risk profile. At each age, four different

Table 22 Cost-effectiveness (Euro per QALY gained) for the treatment of osteoporosis, hypertension and hyperlipidaemia for women in different risk groups based on a societal perspective. (Adapted from [166])

\begin{tabular}{|c|c|c|c|c|}
\hline \multirow[t]{2}{*}{ Age (years) } & \multicolumn{4}{|c|}{ Risk category } \\
\hline & I & II & III & IV \\
\hline \multicolumn{5}{|l|}{ Osteoporosis } \\
\hline 50 & 80,000 & 53,000 & 29,000 & 21,000 \\
\hline 60 & 50,000 & 34,000 & 22,000 & 16,000 \\
\hline 70 & 36,000 & 22,000 & 14,000 & 7,600 \\
\hline 80 & 21,000 & 9,300 & 5,500 & c.s. \\
\hline \multicolumn{5}{|l|}{ Hypertension } \\
\hline 50 & 64,000 & 61,000 & 44,000 & 23,000 \\
\hline 60 & 46,000 & 37,000 & 33,000 & 21,000 \\
\hline 70 & 33,000 & 32,000 & 29,000 & 24,000 \\
\hline 80 & 37,000 & 35,000 & 34,000 & 31,000 \\
\hline \multicolumn{5}{|c|}{ Hyperlipidaemia } \\
\hline 50 & 41,000 & 27,000 & 13,000 & 5,500 \\
\hline 60 & 40,000 & 27,000 & 19,000 & 16,000 \\
\hline 70 & 36,000 & 32,000 & 26,000 & 26,000 \\
\hline 80 & 43,000 & 38,000 & 36,000 & 36,000 \\
\hline
\end{tabular}


levels of risk were chosen for each disease. For the osteoporosis group, patients were defined according to the T-score for BMD (T-score -2.5 and $-3.0 \mathrm{SD}$ ) with or without a history of a previous fragility fracture. In the hypertension group, women were defined according to systolic blood pressure (140 and $160 \mathrm{~mm} \mathrm{Hg}$, equivalent to stage I and stage II-IV hypertension), with or without type II diabetes and smoking. In the hyperlipidaemia group, women were categorised according to the serum level of total cholesterol (TC) and high density lipoprotein (HDL) cholesterol in combination with diabetes and smoking as shown in Table 21.

The treatments comprised alendronate (70 mg weekly), hydrochlorothiazide ( $25 \mathrm{mg}$ daily), and simvastatin $(20 \mathrm{mg}$ daily). These were chosen since they were the cheapest within one class of first-line drugs. Intervention was compared with no intervention. The expected risk reductions were taken from meta-analyses. A 5-year cholesterol lowering and antihypertensive treatment was cost-effective in all the defined patient groups (Table 22) using a value of SEK 600,000 per QALY gained as a threshold for costeffectiveness (approximately 63,000 Euros), derived from the value that the Swedish authorities put on a statistical life. Treatment of osteoporosis was cost-effective in all populations, except for 50-year old women without a previous vertebral fracture, since the average fracture risks are relatively low in this age group. However, in all other cases the cost per QALY gained was below 63,000 Euros.

Acknowledgements We are grateful to Dr Eugene V. McCloskey, Helena Johansson, Anders Oden, Niklas Zethraeus, Oskar Strom and Bengt Jonsson for their assistance with the health economics.

\section{References}

1. Consensus Development Conference (1993) Diagnosis, prophylaxis and treatment of osteoporosis. Am J Med 94:646-650

2. Kanis JA, Johnell O, Oden A, Sembo I, Redlund-Johnell I, Dawson A et al (2000) Long-term risk of osteoporotic fracture in Malmo. Osteoporos Int 11:669-674

3. Johnell O, Kanis JA (2006) An estimate of the worldwide prevalence and disability associated with osteoporotic fractures. Osteoporos Int 17:1726-1733

4. Kanis JA, Johnell O, on behalf of the Committee of Scientific Advisors of the International Osteoporosis Foundation (2005) Requirements for DXA for the management of osteoporosis in Europe. Osteoporos Int 16:220-238

5. Cooper C, Atkinson EJ, Jacobsen SJ, O'Fallon WM, Melton LJ (1993) A population based study of survival after osteoporotic fractures. Am J Epidemiol 137:1001-1005

6. Kanis JA, Oden A, Johnell O, De Laet C, Jonsson B, Oglesby AK (2003) The components of excess mortality after hip fracture. Bone 32:468-473

7. Murray CJL, Lopez AD (eds) (1996) The global burden of disease and injury series, vol II. Global health statistics: a compendium of incidence, prevalence and mortality estimates for over 200 conditions. Harvard School of Public Health on behalf of the World Health Organization and the World Bank, Harvard University Press, Cambridge, MA

8. Blake GM, Fogelman I (2007) Role of dual-energy X-ray absorptiometry in the diagnosis and treatment of osteoporosis. $\mathrm{J}$ Clin Densitom 10:102-110

9. Engelke K, Gluer CC (2006) Quality and performance measures in bone densitometry. I. Errors and diagnosis. Osteoporos Int 17:1283-1292

10. Gluer CC, Lu Y, Engelke K (2006) Quality and performance measures in bone densitometry. II. Fracture risk. Osteoporos Int $17: 1449-1458$

11. Genant HK, Engelke K, Fuerst T, Glüer CC, Grampp S, Harris ST et al (1996) Non invasive assessment of bone mineral and structure: state of the art. J Bone Miner Res 11:707-730

12. Mazess R, Collick B, Trempe J, Barden H, Hanson J (1998) Performance evaluation of a dual energy X-ray bone densitometer. Calcif Tissue Int 44:228-232

13. World Health Organization (1994) Assessment of fracture risk and its application to screening for postmenopausal osteoporosis. Technical Report Series 843. WHO, Geneva

14. Marshall D, Johnell O, Wedel H (1996) Meta-analysis of how well measures of bone mineral density predict occurrence of osteoporotic fractures. Br Med J 312:1254-1259

15. Glüer CC, for the International Quantitative Ultrasound Consensus Group (1997) Quantitative ultrasound techniques for the assessment of osteoporosis: expert agreement on current status. J Bone Miner Res 12:1280-1288

16. Cummings SR, Black DM, Nevitt MC, Browner W, Cauley J, Ensrud K et al (1993) Bone density at various sites for prediction of hip fractures. The Study of Osteoporotic Fractures Research Group. Lancet 341:72-75

17. Johnell O, Kanis JA, Oden A, Johansson H, De Laet C, Delmas P et al (2005) Predictive value of bone mineral density for hip and other fractures. J Bone Miner Res 20:1185-1194. Erratum (2007) J Bone Miner Res 22:774

18. World Health Organization (2007) Assessment of osteoporosis at the primary health care level. Summary Report of a WHO Scientific Group. WHO, Geneva

19. Kanis JA, on behalf of the World Health Organization Scientific Group (2007) Assessment of osteoporosis at the primary healthcare level. Technical Report. WHO Collaborating Centre, University of Sheffield, Sheffield

20. Looker AC, Orwoll ES, Johnston CC, Lindsay RL, Wahner HW, Dunn WL et al (1997) Prevalence of low femoral bone density in older US adults from NHANES III. J Bone Miner Res 12: 1761-1768

21. Looker AC, Wahner HW, Dunn WL, Calvo MS, Harris TB, Heyse SP (1998) Updated data on proximal femur bone mineral levels of US adults. Osteoporos Int 8:468-486

22. Kanis JA, Glüer CC for the Committee of Scientific Advisors, International Osteoporosis Foundation (2000) An update on the diagnosis and assessment of osteoporosis with densitometry. Osteoporos Int 11:192-202

23. Kanis JA, Melton LJ, Christiansen C, Johnston CC, Khaltaev N (1994) The diagnosis of osteoporosis. J Bone Miner Res 9: 1117-1141

24. Kanis JA, Johnell O, Oden A, Jonsson B, De Laet C, Dawson A (2000) Risk of hip fracture according to the World Health Organization criteria for osteopenia and osteoporosis. Bone 27:585-590

24. Lewiecki EM, Watts NB, McClung MR, Petak SM, Bachrach TK, Shepherd JA et al (2004) Official position of the International Society for Clinical Densitometry. J Clin Endocrinol Metab 89:3651-3655

26. Binkley N, Bilezikian JP, Kendler DL, Leib ES, Lewiecki EM, Petak SM, International Society for Clinical Densitometry (2006) 
Official positions of the International Society for Clinical Densitometry and Executive Summary of the 2005 Position Development Conference. J Clin Densitom 9:4-14

27. Blake GM, Patel R, Knapp KM, Fogelman I (2003) Does the combination of two BMD measurements improve fracture discrimination. J Bone Miner Res 18:1955-1963

28. Kanis JA, Seeman E, Johnell O, Rizzoli R, Delmas P (2005) The perspective of the International Osteoporosis Foundation on the official positions of the International Society for Clinical Densitometry. Osteoporos Int 16:456-459

29. Kanis JA, Johnell O, Oden A, Johansson H, Eisman JA, Fujiwara $S$ et al (2006) The use of multiple sites for the diagnosis of osteoporosis. Osteoporos Int 17:527-534

30. Kanis JA, Delmas P, Burckhardt P, Cooper C, Torgerson D, on behalf of the European Foundation for Osteoporosis and Bone Disease (1997) Guidelines for diagnosis and management of osteoporosis. Osteoporos Int 7:390-406

31. Watts NB (2004) Fundamentals and pitfalls of bone densitometry using dual-energy X-ray absorptiometry (DXA). Osteoporos Int $15: 847-854$

32. Bonaiuti D, Shea B, Iovine R, Negrini S, Robinson V, Kemper $\mathrm{HC}$ et al (2002) Exercise for preventing and treating osteoporosis in postmenopausal women. Cochrane Database Syst Rev 3: CD000333

33. Myers AH, Young Y, Langlois JA (1996) Prevention of falls in the elderly. Bone 18:87S-101S

34. Kannus P, Sievanen H, Palvanen M, Jarvinen T, Parkkari J (2005) Prevention of falls and consequent injuries in elderly people. Lancet 366:1885-1893

35. Oliver D, Connelly JB, Victor CR, Shaw FE, Whitehead A, Genc Y et al (2007) Strategies to prevent falls and fractures in hospitals and care homes and effect of cognitive impairment: systematic review and meta-analyses. BMJ 334:82

36. Sawka AM, Boulos P, Beattie K, Thabane L, Papaioannou A, Gafni A et al (2005) Do hip protectors decrease the risk of hip fracture in institutional and community-dwelling elderly? A systematic review and meta-analysis of randomized controlled trials. Osteoporos Int 16:1461-1474

37. Parker MJ, Gillespie WJ, Gillespie LD (2006) Effectiveness of hip protectors for preventing hip fractures in elderly people: systematic review. BMJ 332:571-574

38. Kiel DP, Magaziner J, Zimmerman S, Ball L, Barton BA, Brown $\mathrm{KM}$ et al (2007) Efficacy of a hip protector to prevent hip fracture in nursing home residents: the HIP PRO randomized controlled trial. JAMA 298:413-422

39. Bischoff-Ferrari HA, Dawson-Hughes B, Willett WC, Staehelin HB, Bazemore MG, Zee RY et al (1999). Effect of Vitamin D on falls: a meta-analysis. JAMA 28:1999-2006

40. Tang B, Eslick GD, Nowson C, Smith C, Bensoussan A (2007) Use of calcium or calcium in combination with vitamin D supplementation to prevent fractures and bone loss in older people: a meta-analysis. Lancet 370:657-666

41. Rizzoli R, Bonjour JP (2004) Dietary protein and bone health. J Bone Miner Res 19:527-531

42. Delmas PD (2002) Treatment of postmenopausal osteoporosis. Lancet 359:2018-2026

43. Boonen S, Body JJ, Boutsen Y, Devogelaer JP, Goemaere S, Kaufman JM et al (2005) Evidence-based guidelines for the treatment of postmenopausal osteoporosis: a consensus document of the Belgian Bone Club. Osteoporos Int 16:239-254

44. Delmas PD, Bjarnason NH, Mitlak BH, Ravoux AC, Shah AS, Huster WJ et al (1997) Effects of raloxifene on bone mineral density, serum cholesterol concentrations, and uterine endometrium in postmenopausal women. N Engl J Med 337:1641-1647

45. Ettinger B, Black DM, Mitlak BH, Knickerbocker RK, Nickelsen T, Genant HK et al (1999) Reduction of vertebral fracture risk in postmenopausal women with osteoporosis treated with raloxifene: results from a 3-year randomized clinical trial. Multiple Outcomes of Raloxifene Evaluation (MORE) Investigators. JAMA 282: 637-645

46. Delmas PD, Genant HK, Crans GG, Stock JL, Wong M, Siris E et al (2003) Severity of prevalent vertebral fractures and the risk of subsequent vertebral and nonvertebral fractures: results from the MORE trial. Bone 33:522-532

47. Cummings SR, Eckert S, Krueger KA, Grady D, Powles TJ, Cauley JA et al (1999) The effect of raloxifene on risk of breast cancer in postmenopausal women: results from the MORE randomized trial. Multiple Outcomes of Raloxifene Evaluation. JAMA 281:2189-2197

48. Vogel VG, Costantino JP, Wickerham DL, Cronin WM, Cecchini RS, Atkins JN et al (2006) Effects of tamoxifen vs raloxifene on the risk of developing invasive breast cancer and other disease outcomes: the NSABP Study of Tamoxifen and Raloxifene (STAR) P-2 trial. JAMA 295:2727-2741

49. Mosca L, Barrett-Connor E, Wenger NK, Collins P, Grady D, Kornitzer $\mathrm{M}$ et al (2001) Design and methods of the Raloxifene Use for The Heart (RUTH) study. Am J Cardiol 88:392-395

50. Barrett-Connor E, Mosca L, Collins P, Geiger MJ, Grady D, Kornitzer M et al (2006) Effects of raloxifene on cardiovascular events and breast cancer in postmenopausal women. N Engl J Med 355:125-137

51. Black DM, Cummings SR, Karpf DB, Cauley JA, Thompson DE, Nevitt MC et al (1996) Randomised trial of effect of alendronate on risk of fracture in women with existing vertebral fractures. Fracture Intervention Trial Research Group. Lancet 348:1535-1541

52. Stevenson M, Lloyd Jones M, De Nigris E, Brewer N, Davis S, Oakley J (2005) A systematic review and economic evaluation of alendronate, etidronate, risedronate, raloxifene and teriparatide for the prevention and treatment of postmenopausal osteoporosis. Health Technol Assess 9:1-160

53. Cranney A, Guyatt G, Griffith L, Wells G, Tugwell P, Rosen C et al (2002) Meta-analyses of therapies for postmenopausal osteoporosis. IX. Summary of meta-analyses of therapies for postmenopausal osteoporosis. Endocr Rev 23:570-578

54. Cummings SR, Black DM, Thompson DE, Applegate WB, Barrett-Connor E, Musliner TA et al (1998) Effect of alendronate on risk of fracture in women with low bone density but without vertebral fractures: results from the Fracture Intervention Trial. JAMA 280:2077-2082

55. Harris ST, Watts NB, Genant HK, McKeever CD, Hangartner T, Keller M et al (1999) Effects of risedronate treatment on vertebral and nonvertebral fractures in women with postmenopausal osteoporosis: a randomized controlled trial. Vertebral Efficacy with Risedronate Therapy (VERT) Study Group. JAMA 282:1344-1352

56. Reginster J, Minne HW, Sorensen OH, Hooper M, Roux C, Brandi ML et al (2000) Randomized trial of the effects of risedronate on vertebral fractures in women with established postmenopausal osteoporosis. Vertebral Efficacy with Risedronate Therapy (VERT) Study Group. Osteoporos Int 11:83-91

57. McClung MR, Geusens P, Miller PD, Zippel H, Bensen WG, Roux C et al (2001) Effect of risedronate on the risk of hip fracture in elderly women. Hip Intervention Program Study Group. N Engl J Med 344:333-340

58. Chesnut IC, Skag A, Christiansen C, Recker R, Stakkestad JA, Hoiseth A et al (2004) Effects of oral ibandronate administered daily or intermittently on fracture risk in postmenopausal osteoporosis. J Bone Miner Res 19:1241-1249

59. Delmas PD, Recker RR, Chesnut CH III, Skag A, Stakkestad JA, Emkey R et al (2004) Daily and intermittent oral ibandronate normalize bone turnover and provide significant reduction in 
vertebral fracture risk: results from the BONE study. Osteoporos Int 15:792-798

60. Reginster JY, Adami S, Lakatos P, Greenwald M, Stepan JJ, Silverman SL et al (2006) Efficacy and tolerability of oncemonthly oral ibandronate in postmenopausal osteoporosis: 2 year results from the MOBILE study. Ann Rheum Dis 65:654-661

61. Delmas PD, Adami S, Strugala C, Stakkestad JA, Reginster JY, Felsenberg D et al (2006) Intravenous ibandronate injections in postmenopausal women with osteoporosis: one-year results from the Dosing Intravenous Administration Study. Arthritis Rheum 54:1838-1846

62. Reid IR, Brown JP, Burckhardt P, Horowitz Z, Richardson P, Trechsel U (2002) Intravenous zoledronic acid in postmenopausal women with low bone mineral density. N Engl J Med 346:653-661

63. Black DM, Delmas PD, Eastell R, Reid IR, Boonen S, Cauley JA et al (2007) Once-yearly zoledronic acid for treatment of postmenopausal osteoporosis. N Engl J Med 356:1809-1822

64. Lyles KW, Colon-Emeric CS, Magaziner JS, Adachi JD, Pieper $\mathrm{CF}$, Mautalen $\mathrm{C}$ et al, the HORIZON Recurrent Fracture Trial (2007) Zoledronic acid and clinical fractures and mortality after hip fracture. N Engl J Med 357:1799-1809

65. Neer RM, Arnaud CD, Zanchetta JR, Prince R, Gaich GA, Reginster JY et al (2001) Effect of parathyroid hormone (1-34) on fractures and bone mineral density in postmenopausal women with osteoporosis. N Engl J Med 344:1434-1441

66. Shrader SP, Raggucci KR (2005) Parathyroid hormone (1-84) and treatment of osteoporosis. Ann Pharmacother 39:1511-1516

67. Prince R, Sipos A, Hossain A, Syversen U, Ish-Shalom S, Marcinowska E et al (2005) Sustained nonvertebral fragility fracture risk reduction after discontinuation of teriparatide treatment. J Bone Miner Res 20:1507-1513

68. Meunier PJ, Roux C, Seeman E, Ortolani S, Badurski JE, Spector TD et al (2004) The effects of strontium ranelate on the risk of vertebral fracture in women with postmenopausal osteoporosis. N Engl J Med 350:459-468

69. Reginster JY, Seeman E, De Vernejoul MC, Adami S, Compston J, Phenekos C et al (2005) Strontium ranelate reduces the risk of nonvertebral fractures in postmenopausal women with osteoporosis: Treatment of Peripheral Osteoporosis (TROPOS) study. J Clin Endocrinol Metab 90:2816-2822

70. Rabenda V, Hanssens L, De Ceulaer F, Reginster JY (2005) Is there any interest in combining treatments in osteoporosis? Curr Rheumatol Rev 1:49-55

71. Ettinger B, San Martin J, Crans G, Pavo I (2004) Differential effects of teriparatide on BMD after treatment with raloxifene or alendronate. J Bone Min Res 19:745-750

72. Black DM, Greenspan SL, Ensrud KE, Palermo L, McGowan JA, Lang TF et al (2003) The effects of parathyroid hormone and alendronate alone or in combination in postmenopausal osteoporosis. N Engl J Med 249:1207-1215

73. Finkelstein JS, Hayes A, Hunzelman JL, Wyland JJ, Lee H, Neer RM (2003) The effects of parathyroid hormone, alendronate, or both in men with osteoporosis. N Engl J Med 349:1216-1226

74. Deal C, Omizo M, Schwartz EN, Eriksen EF, Cantor P, Wang J et al (2005) Combination teriparatide and raloxifene therapy for postmenopausal osteoporosis: results from a 6-month doubleblind placebo controlled trial. J Bone Miner Res 20:1905-1911

75. Black DM, Bilezikian JP, Ensrud KE, Greenspan SL, Palermo L, Hue T et al (2005) One year alendronate after one year of parathyroid hormone (1-84) for osteoporosis. N Engl J Med 353:555-565

76. Reginster JY (1991) Effect of calcitonin on bone mass and fracture rates. Am J Med 91(5B):19S-22S

77. Plosker GL, McTavis D (1996) Intranasal salcaltonin: a review of its pharmacological properties and role in the management of postmenopausal osteoporosis. Drugs Aging 8:378-400
78. Cranney A, Tugwell P, Zyatruk N, Robinson V, Weaver B, Shea B et al (2002) Meta-analysis of calcitonin for the treatment of postmenopausal osteoporosis. Endocr Rev 23:540-551

79. Chesnut CH III, Silverman S, Andriano K, Genant H, Giomana A, Harris S et al (2000) A randomized trial of nasal spray salmon calcitonin in postmenopausal women with established osteoporosis: the prevent recurrence of osteoporotic fracture study. PROOF Study Group. Am J Med 109:267-276

80. Kanis JA, Johnell O, Gullberg BO, Allander E, Dilsen G, Gennari C (1992) Evidence for efficacy of drugs affecting bone metabolism in preventing hip fracture. BMJ 305:1124-1128

81. Torgerson DJ, Bell-Syer SE (2001) Hormone replacement therapy and prevention of non-vertebral fractures: a metaanalysis of randomized trials. JAMA 285:2891-2897

82. Cauley JA, Robbins J, Chen Z, Cummings SR, Jackson RD, LaCroix AZ et al (2003) Effects of estrogen plus progestin on risk of fracture and bone mineral density: the Women's Health Initiative randomized trial. JAMA 290:1729-1738

83. Sornay-Rendu E, Garnero P, Munoz F, Duboeuf F, Delmas PD (2003) Effect of withdrawal of hormone replacement therapy on bone mass and bone turnover: the OFELY study. Bone 33:159-166

84. Bagger YZ, Tanko LG, Alexandersen P, Hansen HB, Mollgaard A, Ravn P et al (2004) Two to three years of hormone replacement treatment in healthy women have long-term preventive effects on bone mass and osteoporotic fractures: the PERF study. Bone 34:728-735

85. Roussow JE, Anderson GL, Prentice RL, LaCroix AZ, Kooperberg C, Stefanick ML et al (2002) Risks and benefits of estrogen plus progestin in healthy postmenopausal women: principal results from the Women's Health Initiative randomized controlled trial. JAMA 288:321-333

86. Wassertheil-Smoller S, Hendrix SL, Limacher M, Heiss G, Kooperberg C, Baird A et al (2003) Effect of estrogen plus progestin on stroke in postmenopausal women: the Women's Health Initiative: a randomized trial. JAMA 289:2673-2684

87. Chlebowski RT, Hendrix SL, Langer RD, Stefanick ML, Gass M, Lane D et al (2003) Influence of estrogen plus progestin on breast cancer and mammography in healthy postmenopausal women: the Women's Health Initiative Randomized Trial. JAMA 289:3243-3253

88. Shumaker SA, Legault C, Rapp SR, Thal L, Wallace RB, Ockene JK et al (2003) Estrogen plus progestin and the incidence of dementia and mild cognitive impairment in postmenopausal women: the Women's Health Initiative Memory Study: a randomized controlled trial. JAMA 289:2651-2662

89. Hays J, Ockene JK, Brunner RL, Kotchen JM, Manson JE, Patterson RE et al (2003) Effects of estrogen plus progestin on health-related quality of life. N Engl J Med 348:1839-1854

90. Anderson GL, Limacher M, Assaf AR, Bassford T, Beresford SA, Black H et al (2004) Effects of conjugated equine estrogen in postmenopausal women with hysterectomy: the Women's Health Initiative randomized controlled trial. JAMA 291:17011712

91. McCloskey E, Selby P, Davies M, Robinson J, Francis RM, Adams J et al (2004) Clodronate reduces vertebral fracture risk in women with postmenopausal or secondary osteoporosis: results of a double-blind, placebo-controlled 3-year study. J Bone Miner Res 19:728-736

92. Richy F, Ethgen O, Bruyere O, Reginster JY (2004) Efficacy of alfacalcidol and calcitriol in primary and corticosteroid-induced osteoporosis: a meta-analysis of their effects on bone mineral density and fracture rate. Osteoporos Int 15:301-310

93. Richy F, Schacht E, Bruyere O, Ethgen O, Gourlay M, Reginster JY (2005) Vitamin D analogs versus native vitamin D in preventing bone loss and osteoporosis-related fractures: a comparative meta-analysis. Calcif Tissue Int 76:176-186 
94. Tilyard MW, Spears GF, Thomson J, Dovey S (1992) Treatment of postmenopausal osteoporosis with calcitriol or calcium. N Engl J Med 326:357-362

95. Gallagher JC, Rapuri PB, Smith LM (2007) Age related decrease in creatinine clearance is associated with an increase in number of falls in untreated women but not in women receiving calcitriol treatment. J Clin Endocrinol Metab 92:51-58

96. McCloskey EV, Beneton M, Charlesworth D, Kayan K, deTakats D, Dey A et al (2007) Clodronate reduces the incidence of fractures in community dwelling elderly women unselected for osteoporosis: results of a double-blind, placebo-controlled randomized study. J Bone Miner Res 22:135-141

97. Lekkerkerker F, Kanis JA, Alsayed N, Bouvenot G, Burlet N, Cahall D et al (2007) Adherence to treatment of osteoporosis: a need for study. Osteoporos Int 18:1311-1317

98. Solomon DH, Avorn J, Katz JN, Finkelstein JS, Arnold M, Polinski JM et al (2006) Compliance with osteoporosis medications. Arch Intern Med 165:2414-2419

99. Reginster JY, Rabenda V (2006) Adherence to anti-osteoporotic treatment: does it really matter? Future Rheumatol 1:37-40

100. Caro JJ, Ishak KJ, Huybrechts KF, Raggio G, Naujoks C (2004) The impact of compliance with osteoporosis therapy on fracture rates in actual practice. Osteoporos Int 15:1003-1008

101. Carr AJ, Thompson PW, Cooper C (2006) Factors associated with adherence and persistence to bisphosphonate therapy in osteoporosis: a cross-sectional survey. Osteoporos Int 17:16381644

102. Hochberg MC, Greenspan S, Wasnich RD, Miller P, Thompson DE, Ross PD (2002) Changes in bone density and turnover explain the reductions in incidence of nonvertebral fractures that occur during treatment with antiresorptive agents. J Clin Endocrinol Metab 87:1586-1592

103. Delmas PD, Li Z, Cooper C (2004) Relationship between changes in bone mineral density and fracture risk reduction with antiresorptive drugs: some issues with meta-analyses. J Bone Miner Res 19:330-337

104. Cummings SR, Karpf DB, Harris F, Genant HK, Ensrud K, LaCroix AZ et al (2006) Improvement in spine bone density and reduction in risk of vertebral fractures during treatment with antiresorptive drugs. Am J Med 112:281-289

105. Watts NB, Geusens P, Barton IP, Felsenberg D (2005) Relationship between changes in BMD and non-vertebral fracture incidence associated with risedronate: reduction in risk of nonvertebral fracture is not related to change in BMD. J Bone Miner Res 20:2097-2104

106. Sarkar S, Mitlak BH, Wong M, Stock JL, Black DM, Harper KD (2002) Relationships between bone mineral density and incident vertebral fracture risk with raloxifene therapy. J Bone Miner Res 17:1-10

107. Chen P, Miller PD, Delmas PD, Misurski DA, Krege JH (2006) Change in lumbar spine BMD and vertebral fracture risk reduction in teriparatide treated postmenopausal women with osteoporosis. J Bone Miner Res 21:1785-1790

108. Bruyère $\mathrm{O}$, Roux $\mathrm{C}$, Detilleux $\mathrm{J}$, Slosman DO, Spector TD et al (2007) Relation between bone mineral density changes and fracture risk reduction in patients treated with strontium ranelate. J Clin Endocrinol Metab 92:3076-3081

109. Garnero P, Delmas PD (2001) Biochemical markers of bone turnover in osteoporosis. In: Marcus M, Feldman D, Kelsey J (eds) Osteoporosis, vol 2. Academic, New York, pp 459-477

110. Delmas PD, Eastell R, Garnero P, Seibel MJ, Stepan J (2000) The use of biochemical markers of bone turnover in osteoporosis. Committee of Scientific Advisors of the International Osteoporosis Foundation. Osteoporos Int 11(6):S1-S76

111. Ravn P, Hosking D, Thompson D, Cizza G, Wasnich RD, McClung $\mathrm{M}$ et al (1999) Monitoring of alendronate treatment and prediction of effect on bone mass by biochemical markers in the early postmenopausal intervention cohort study. J Clin Endocrinol Metab 84:2363-2368

112. Bjarnason NH, Sarkar S, Duong T, Mitlak B, Delmas PD, Christiansen C (2001) Six and twelve month changes in bone turnover are related to reduction in vertebral fracture risk during 3 years of raloxifene treatment in postmenopausal osteoporosis. Osteoporos Int 12:922-930

113. Eastell R, Barton I, Hannon RA, Chines A, Garnero P, Delmas PD (2003) Relationship of early changes in bone resorption to the reduction in fracture risk with risedronate. J Bone Miner Res 18:1051-1056

114. Bauer DC, Black DM, Garnero P, Hochberg M, Ott S, Orloff J et al (2004) Change in bone turnover and hip, non-spine, and vertebral fracture in alendronate-treated women: the Fracture Intervention Trial. J Bone Miner Res 19:1250-1258

115. Delmas PD, Vrijens B, Eastell R, Roux C, Pols H, Ringe J et al (2007) Effect of monitoring bone turnover markers on persistence with risedronate treatment of postmenopausal osteoporosis: the IMPACT study. J Clin Endocrinol Metab 92:1296-1304

116. Bauer DC, Garnero P, Bilezikian JP, Greenspan SL, Ensrud KE, Rosen CJ et al (2006) Short-term changes in bone turnover markers and bone mineral density response to parathyroid hormone in postmenopausal women with osteoporosis. J Clin Endocrinol Metab 91:1370-1375

117. Chen P, Satterwhite JH, Licata AA, Lewiecki EM, Sipos AA, Misurski DM et al (2005) Early changes in biochemical markers of bone formation predict BMD response to teriparatide in postmenopausal women with osteoporosis. J Bone Miner Res 20:962-970

118. Kanis JA, Black D, Cooper C, Dargent P, Dawson-Hughes B, De Laet C (2002) A new approach to the development of assessment guidelines for osteoporosis. Osteoporos Int 13:527-536

119. Kanis JA, Johnell O, Oden A, De Laet C, Jonsson B, Dawson A (2001) Ten year risk of osteoporotic fracture and the effect of risk factors on screening strategies. Bone 30:251-258

120. Hui SL, Slemenda CW, Johnston CC (1988) Age and bone mass as predictors of fracture in a prospective study. J Clin Invest 81:1804-1809

121. Kanis JA, Johnell O, Oden A, Dawson A, De Laet C, Jonsson B (2001) Ten year probabilities of osteoporotic fractures according to BMD and diagnostic thresholds. Osteoporos Int 12:989-995

122. Cummings SR, Nevitt MC, Browner WS, Stone K, Fox KM, Ensrud KE et al (1995) Risk factors for hip fracture in white women. N Engl J Med 332:767-773

123. Ribot C, Pouilles JM, Bonneu M, Tremollieres F (1992) Assessment of the risk of postmenopausal osteoporosis using clinical risk factors. Clin Endocrinol 36 225-228

124. Poor G, Atkinson EJ, O'Fallon WM, Melton LJ III (1995) Predictors of hip fractures in elderly men. J Bone Miner Res 10:1900-1907

125. Kanis JA (2002) Diagnosis of osteoporosis and assessment of fracture risk. Lancet 359:1929-1936

126. Kanis JA, Borgstrom F, De Laet C, Johansson H, Johnell O, Jonsson B et al (2005) Assessment of fracture risk. Osteoporos Int 16:581-589

127. De Laet C, Kanis JA, Oden A, Johanson H, Johnell O, Delmas $P$ et al (2005) Body mass index as a predictor of fracture risk: a meta-analysis. Osteoporos Int 16:1330-1338

128. Klotzbuecher CM, Ross PD, Landsman PB, Abbot TA, Berger M (2000) Patients with prior fractures have increased risk of future fractures: a summary of the literature and statistical synthesis. J Bone Miner Res 15:721-727

129. Kanis JA, Johansson H, Oden A, Johnell O, De Laet C, Eisman JA et al (2004) A family history of fracture and fracture risk: a meta-analysis. Bone 35:1029-1037 
130. Kanis JA, Johnell O, Oden A, Johansson H, De Laet C, Eisman JA et al (2006) Smoking and fracture risk: a meta-analysis. Osteoporos Int 16:155-162

131. Van Staa TP, Leufkens HGM, Cooper C (2002) The epidemiology of corticosteroid-induced osteoporosis: a meta-analysis. Osteoporos Int 13:777-787

132. Kanis JA, Johansson H, Oden A, Johnell O, de Laet C, Melton III LJ et al (2000) A meta-analysis of prior corticosteroid use and fracture risk. J Bone Miner Res 19:893-899

133. Kanis JA, Johansson H, Johnell O, Oden A, De Laet C, Eisman JA et al (2005) Alcohol intake as a risk factor for fracture. Osteoporos Int 16:737-742

134. Johnell O, Oden A, De Laet C, Garnero P, Delmas PD, Kanis JA (2002) Biochemical indices of bone turnover and the assessment of fracture probability. Osteoporos Int 13:523-526

135. Royal College of Physicians (2002) Glucocorticoid-induced osteoporosis. Guidelines on prevention and treatment. Bone and Tooth Society of Great Britain, National Osteoporosis Society and Royal College of Physicians. Royal College of Physicians, London

136. Committee for Medicinal Products for Human Use (CHMP) (2006) Guideline on the evaluation of medicinal products in the treatment of primary osteoporosis. CHMP, London

137. Kanis JA, Adams J, Borgström F, Cooper C, Jönsson B, Preedy D et al (2008) The cost-effectiveness of alendronate in the management of osteoporosis. Bone 42(1):4-15

138. McCloskey E, Johansson H, Oden A, Kanis JA (2007) Comparison of European and WHO strategies for the identification of women at risk of hip fracture. Osteoporos Int 18(1):S23

139. Dyslipidaemia Advisory Group on behalf of the Scientific Committee of the National Heart Foundation of New Zealand (1996) National Heart Foundation Clinical Guidelines for the assessment and management of dyslipidaemia. NZ Med J 109:224-232

140. Kanis JA, Johnell O, De Laet C, Jonnson B, Oden A, Ogelsby AK (2002) International variations in hip fracture probability: implications for risk assessment. J Bone Miner Res 17:1237-1244

141. Murray CJL, Lopez AP (1996) Global and regional descriptive epidemiology of disability. Incidence, prevalence, health expectancies and years lived with disability. In: Murray CJL, Lopez $\mathrm{AD}$ (eds) The global burden of disease: a comprehensive assessment of mortality and disability from diseases, injuries and risk factors in 1990 and projected to 2020. Cambridge University Press, Cambridge, pp 201-246

142. Persson U, Hjelmgren J (2003) Health services need knowledge of how the public values health. Lakartidningen 100:3436-3437

143. Eichler HG, Kong SX, Gerth WC et al (2004) Use of costeffectiveness analysis in health-care resource allocation decisionmaking: how are cost-effectiveness thresholds expected to emerge? Value Health 7:518-528

144. Kanis JA, Jonsson B (2002) Economic evaluation of interventions for osteoporosis. Osteoporos Int 13:765-767

145. World Health Organization (2001) Macroeconomics and health: investing in health for economic development: report of the Commission on Macroeconomics and Health. World Health Organization, Geneva

146. Fleurence RL, Iglesias CP, Torgerson, DJ (2006) Economic evaluations of interventions for the prevention and treatment of osteoporosis: a structured review of the literature. Osteoporos Int $17: 29-40$

147. Zethraeus N, Ben Sedrine W, Caulin F, Corcaud S, Gathon HJ, Haim M (2002) Models for assessing the cost-effectiveness of the treatment and prevention of osteoporosis. Osteoporos Int $13: 841-857$

148. Kanis JA, Borgstrom F, Zethraeus N, Johnell O, Oden A, Jonsson B (2005) Intervention thresholds for osteoporosis in the UK. Bone 36:22-32
149. Zethraeus N, Borgström F, Ström O, Kanis JA, Jönsson B on behalf of the Committee of Scientific Advisors of the International Osteoporosis Foundation (2007) Cost-effectiveness of the treatment and prevention of osteoporosis - a review of the literature and a reference model. Osteoporos Int 18:9-23

150. Kanis JA, Johnell O, Oden A, Borgstrom F, Johansson H, De Laet $C$ et al (2005) Intervention thresholds for osteoporosis in men and women: a study based on data from Sweden. Osteoporos Int 16:6-14

151. Kanis JA, Johnell O, Oden A, De Laet C, Oglesby A, Jonsson B (2002) Intervention thresholds for osteoporosis. Bone 31:26-31

152. Johannesson M, Jonsson B (1993) Economic evaluation of osteoporosis prevention. Health Policy 24:103-124

153. Borgstrom F, Johnell O, Kanis JA, Jonnson B, Rehnberg C (2006) At what hip fracture risk is it cost-effective to treat? International intervention thresholds for the treatment of osteoporosis. Osteoporos Int 17:1459-1471

154. Van Staa TP, Geusens P, Zhang B, Leufkens HG, Boonen A, Cooper C (2007) Individual fracture risk and the cost-effectiveness of bisphosphonates in patients using oral glucocorticoids. Rheumatology (Oxford) 46:460-466

155. Cauley JA, Norton L, Lippman ME, Eckert S, Krueger KA, Purdie DW et al (2001) Continued breast cancer risk reduction in postmenopausal women treated with raloxifene: 4-year results from the MORE trial. Multiple outcomes of raloxifene evaluation. Breast Cancer Res Treat 65:125-134. Erratum in: Breast Cancer Res Treat 2001 67:191

156. Royal College of Physicians (1999) Osteoporosis: clinical guidelines for the prevention and treatment. Royal College of Physicians, London

157. Royal College of Physicians and Bone and Tooth Society of Great Britain (2000) Update on pharmacological interventions and an algorithm for management. Royal College of Physicians, London

158. Kanis JA, Borgstrom F, Johnell O, Jonsson B (2004) Costeffectiveness of risedronate for the treatment of osteoporosis and prevention of fractures in postmenopausal women. Osteoporos Int 15:862-871

159. Kanis JA, Borgstrom F, Johnell O, Oden A, Sykes D, Jonsson B (2005) Cost-effectiveness of raloxifene in the UK. An economic evaluation based on the MORE study. Osteoporosis Int 16:15-25

160. Strom O, Borgstrom F, Sen SS, Boonen S, Haentjens P, Johnell $\mathrm{O}$ et al (2007) Cost-effectiveness of alendronate in the treatment of postmenopausal women in 9 European countriesan economic evaluation based on the fracture intervention trial. Osteoporos Int 18:1047-1061

161. National Institute for Health and Clinical Excellence (2007) Final appraisal determination. Alendronate, etidronate, risedronate, raloxifene, strontium ranelate and teriparatide for the secondary prevention of osteoporotic fragility fractures in postmenopausal women. NICE, London

162. National Institute for Health and Clinical Excellence (2007) Final appraisal determination. Alendronate, etidronate, risedronate, raloxifene and strontium ranelate for the primary prevention of osteoporotic fragility fractures in postmenopausal women. NICE, London

163. Delmas PD, Siris E (2008) NICE recommendations for the prevention of osteoporotic fractures in postmenopausal women. Bone 42(1):16-18

164. National Institute for Clinical Excellence (2004) Guide to the methods of technology appraisal. Abbo Litho Sales, London

165. Kanis JA, Stevenson M, McCloskey EV, Davis S, Lloyd-Jones M (2007) Glucocorticoid-induced osteoporosis: a systematic review and cost-utility analysis. Health Technol Assess 11:1-256

166. Zethraeus N, Ström O, Borgström F, Kanis JA, Jönsson B (2007) The cost-effectiveness of the treatment of osteoporosis, hypertension and hyperlipidaemia in Sweden. Osteoporos Int 18:9-23 